\title{
Engineering of Electron Affinity and Interfacial Charge Transfer of Graphene for Self-powered Non-enzymatic Biosensor Applications
}

Mohamed Fathi Sanad a, b, Venkata S.N. Chava a, Ahmed Esmail Shalan c, d, Lissette Garcia Enriquez ${ }^{\text {a, }}$ Ting Zheng e, Srikanth Pilla e, f, g, h, Sreeprasad T. Sreenivasan a *

a Department of Chemistry and Biochemistry, The University of Texas at El Paso, $500 \mathrm{~W}$. University Avenue, El Paso, Texas 79968, USA.

b Department of Environmental Sciences and Engineering, The University of Texas at El Paso, 500 W. University Avenue, El Paso, Texas 79968, USA.

c BCMaterials-Basque Center for Materials, Applications and Nanostructures, Martina Casiano, UPV/EHU Science Park, Barrio Sarriena s/n, Leioa 48940, Spain.

d Central Metallurgical Research and Development Institute (CMRDI), P.O. Box 87, Helwan, Cairo 11421, Egypt.

e Department of Automotive Engineering, Clemson University, 4 Research Drive, Greenville, South Carolina 29607, United States.

f Clemson Composites Centre, Clemson University, Greenville, South Carolina 29607, United States.

g Department of Materials Science and Engineering, Clemson University, Clemson, South Carolina 29602, United States.

h Department of Mechanical Engineering, Clemson University, Clemson, South Carolina 29602, United States.

* Corresponding Author: Sreeprasad T. Sreenivasan; Email: sreenivasan@utep.edu, Phone number; +1 (915) 747-6833, https://orcid.org/0000-0002-5728-0512

KEYWORDS. Interfacial engineering; Band alignment, Graphene acid; Rare earth oxide; Heterostructure, Amperometric sensor; Nonenzymatic glucose biofuel cells; Self-powered biosensors. 


\section{Contents}

Supporting information 1: Experimental details.

Supporting information 2: SEM study.

Supporting information 3: HR-TEM and EDS mapping of the $\mathrm{Sm}_{2} \mathrm{O}_{3} /$ GA heterostructure.

Supporting information 4: XRD of reduced graphene oxide(rGO) and graphene acid (GA)

Supporting information 5: High Resolution-XPS study of $\mathrm{Sm}_{2} \mathrm{O}_{3} /$ GA heterostructure.

Supporting information 6: Raman spectrum of the $\mathrm{Sm}_{2} \mathrm{O}_{3} / \mathrm{GA}$ Heterostructure.

Supporting information 7: Raman study of the $\mathrm{Sm}_{2} \mathrm{O}_{3} /$ GA Heterostructure.

Supporting information 8: Electrochemical characterization of glucose oxidation.

Supporting information 9: -point probe conductivity measurements.

Supporting information 10: ${ }^{13} \mathrm{C}-\mathrm{NMR}$ characterization of the glucose oxidation to Gluconolactone.

Supporting information 11: EIS study of $\mathrm{Sm}_{2} \mathrm{O}_{3} / \mathrm{GA}$ (different loading ratios).

Supporting information 12: ECSA study of the as prepared electrocatalysts.

Supporting information 13: HOMO- LUMO calculation using electrochemistry.

Supporting information 14: DFT, Idealized structures, and bond length calculations.

Supporting information 15: Glucose oxidation active sites.

Supporting information 16: Catalyst reusability study.

Supporting information 17: Idealized structures and ORR active sites of graphene acid.

Supporting information 18: Electrochemical characterization of the GBFC. 


\section{Supporting information 1: Experimental Details.}

\subsection{Chemicals}

Fluorinated graphite, Sodium borohydride, Nitric acid, Sulfuric acid, Phosphate Buffered Saline (Pbs), Sodium chloride, Hydrochloric acid, graphite, Hydrogen peroxide, Potassium permanganate, hydrazine hydrate $\left(\mathrm{NH}_{2} \mathrm{NH}_{2} \cdot \mathrm{H}_{2} \mathrm{O}\right)$, Sodium hydroxide, Glucose, ethyl alcohol and samarium nitrate were purchased from Sigma-Aldrich. All reagents were analytical grade and used as received without further purification.

\subsection{Materials synthesis}

The rGO was synthesized using the modified Hummers method ${ }^{1}$. Typically, sulfuric, and phosphoric acid $(9 / 1 \mathrm{v} / \mathrm{v})$ was mixed and stirred for $10 \mathrm{~min}$. Then, graphite powder was added to this suspension under constant stirring. Potassium permanganate $\left(\mathrm{KMnO}_{4}\right)$ was added gradually to the solution to oxidize the graphite. This mixture was stirred $(\sim 6 \mathrm{~h})$ until the solution turned to a dark green color. Excess potassium permanganate was removed using hydrogen peroxide $\left(\mathrm{H}_{2} \mathrm{O}_{2}\right){ }^{1}$. After that, the sample solution was washed several times with deionized (DI) water followed by vacuum-filtration to obtain the powder sample. Subsequently, this powder sample was dried in an oven at $50{ }^{\circ} \mathrm{C}$ for two days and stored for further use. The synthesis of GA included two steps ${ }^{2}$. First, fluorinated graphite $(120 \mathrm{mg}$ ) was reacted with $\mathrm{NaCN}(800 \mathrm{mg})$ to produce cyano graphene. Later, we added nitric acid ( $65 \mathrm{wt} \%$ ) to cyano graphene, and the solution was further diluted to $20 \mathrm{wt} \%$ by adding water. This solution was stirred for $12 \mathrm{~h}$ and then vacuum filtered to obtain the GA powder sample. Synthesis of $\mathrm{Sm}_{2} \mathrm{O}_{3} / \mathrm{GA}$ heterostructure was carried out by in-situ reduction of Samarium (III) nitrate and GA mixtures using sodium borohydride and reflux for $10 \mathrm{~h}$ and at $130^{\circ} \mathrm{C}$. $\mathrm{Sm}_{2} \mathrm{O}_{3} / \mathrm{GA}$ samples with different $\mathrm{Sm}_{2} \mathrm{O}_{3}$ loading were synthesized by varying the amount of samarium nitrate in the range of 2-30 ppm.

\subsection{Material Characterization}

Structural characterization (XRD) of the rGO, GA, and $\mathrm{Sm}_{2} \mathrm{O}_{3} / \mathrm{GA}$ were performed using a Bruker X-

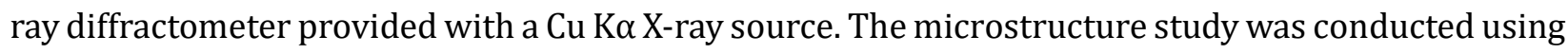
Hitachi SU 3500 SEM. For FE-SEM characterization, the as-prepared materials were first dispersed in IPA and then drop-casted onto the $\mathrm{Si} / \mathrm{SiO}_{2}$ substrates. SEM images were also obtained using a fieldemission gun SEM (Quanta 400 FEG FEI). NTEGRA AFM (NT-MDT) system with a-Si cantilever is used for AFM topographical measurements of GA samples. The samples were dropped cast on a silicon substrate. NTEGRA SPECTR-II system (NT-MDT) equipped with a $532 \mathrm{~nm}$ laser excitation source was used for Raman spectroscopy studies, where the samples were deposited on a silicon substrate. For the HRTEM analysis, the samples were drop-casted on a carbon-coated Cu grid and analyzed using a H9500 (HITACHI) HRTEM equipped with a LaB6 electron gun, operated at an accelerating voltage of $300 \mathrm{kV}$, resolution $0.1 \mathrm{~nm}$. XPS measurements were carried out in PHI Versa-Probe III Scanning ESCA Microprobe equipped with an $\mathrm{Mg} \mathrm{K \alpha}=1253.6 \mathrm{eV}$ source. The binding energies obtained in the XPS spectral range were corrected for specimen charging effects using the $\mathrm{C} 1 \mathrm{~s}$ level at the energy of 284.5 $\mathrm{eV}$ as a reference. Conductivity measurements the spin-coated films of materials ( $\mathrm{rGO}, \mathrm{GA}, \mathrm{Sm}_{2} \mathrm{O}_{3} / \mathrm{GA}$ ). were conducted using 2-point probe technique. We used ITO coated glass as substrates for the spin coating of catalysts films, and silver paint was used to make electrical contact with the probe tip. 
Supporting information 2: SEM study.

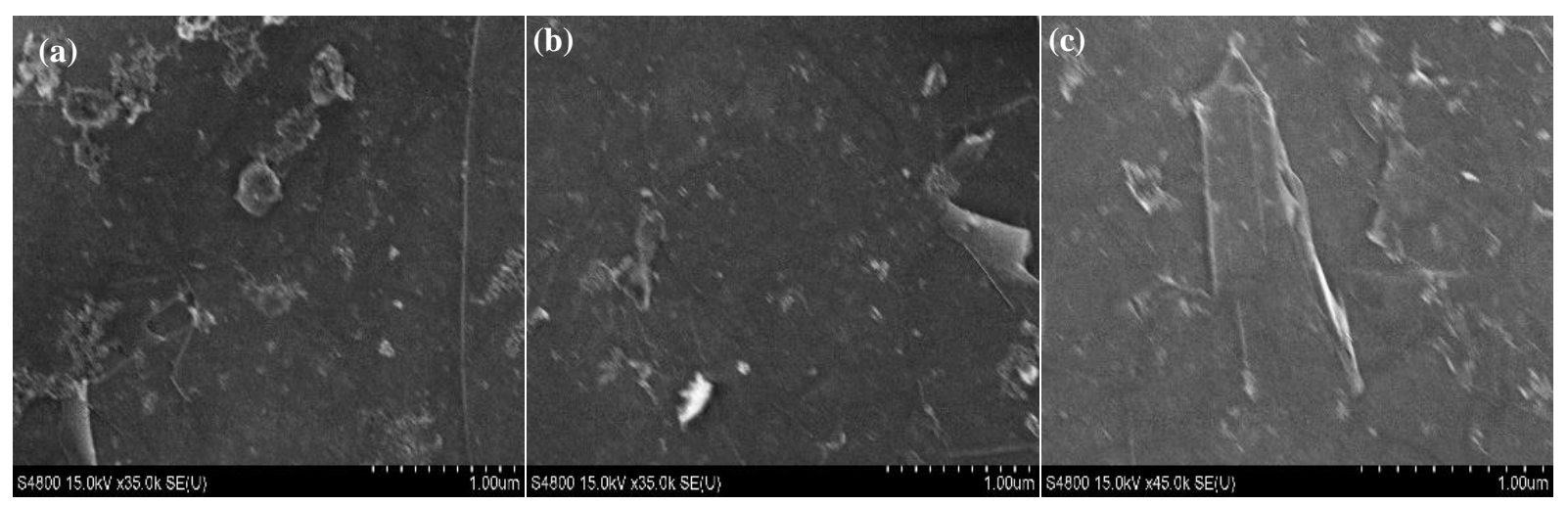

Figure S1. (a-c) FESEM images of the as-prepared $\mathrm{Sm}_{2} \mathrm{O}_{3} / \mathrm{GA}$ nanocomposite sample. 
Supporting information 3: HR-TEM and EDS mapping of the $\mathrm{Sm}_{2} \mathrm{O}_{3} /$ GA heterostructure.
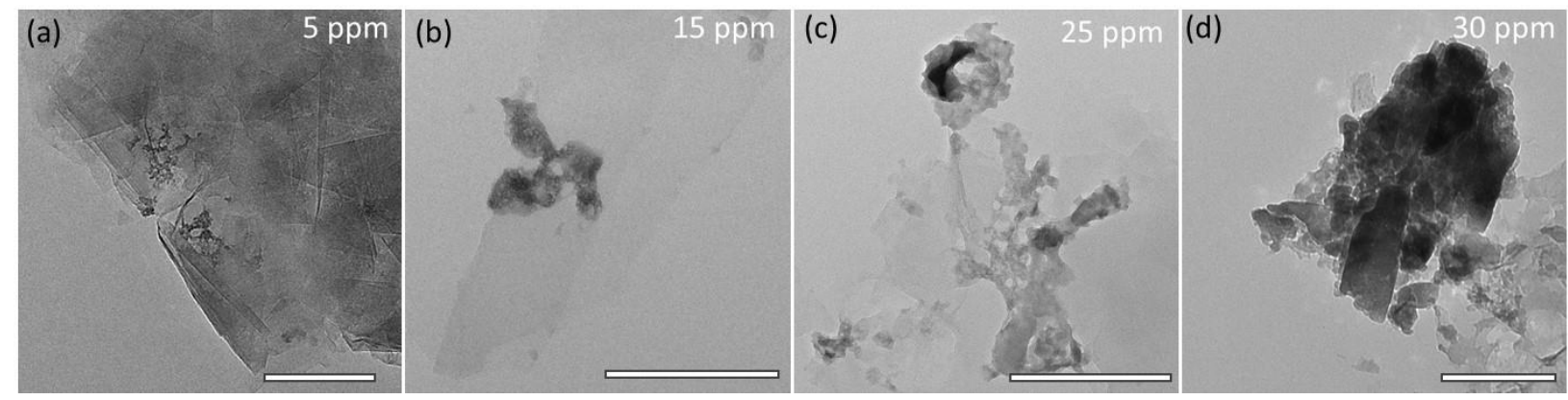

Figure S2. HRTEM of the as prepared $\mathrm{Sm}_{2} \mathrm{O}_{3} / \mathrm{GA}$ catalyst with different loading ratio (a) $5 \mathrm{ppm}$; (b) $10 \mathrm{ppm}$ (c) $25 \mathrm{ppm}$ and $(\mathrm{d}) 30 \mathrm{ppm}($ Scale bar $=500 \mathrm{~nm})$.

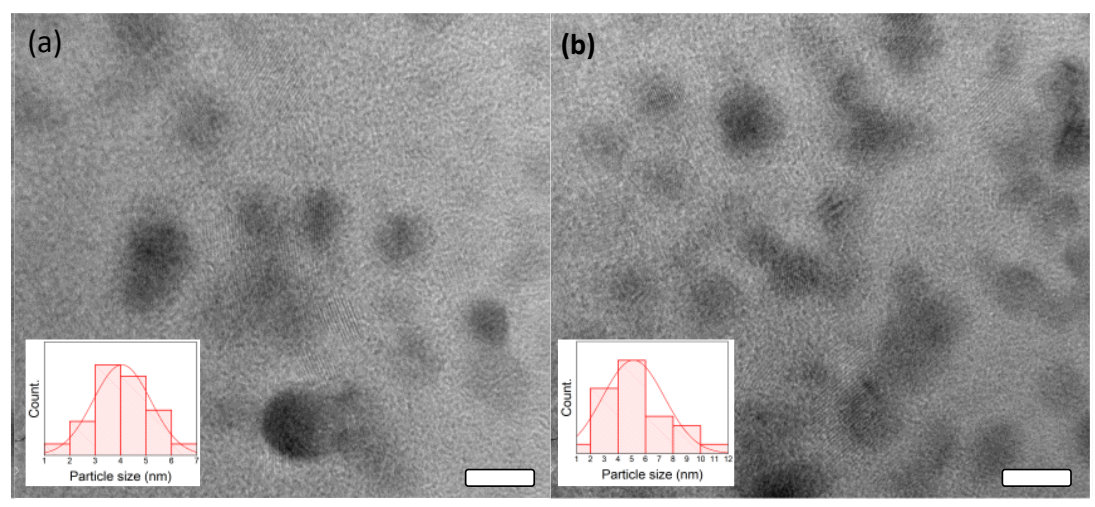

Figure S3. (a) and (b) HR-TEM of as-prepared $\mathrm{Sm}_{2} \mathrm{O}_{3} / \mathrm{GA}$ catalyst (Scale bar $=5 \mathrm{~nm}$ ); Inset represents the average crystallite size distribution of $\mathrm{Sm} 2 \mathrm{O} 3$ particles.
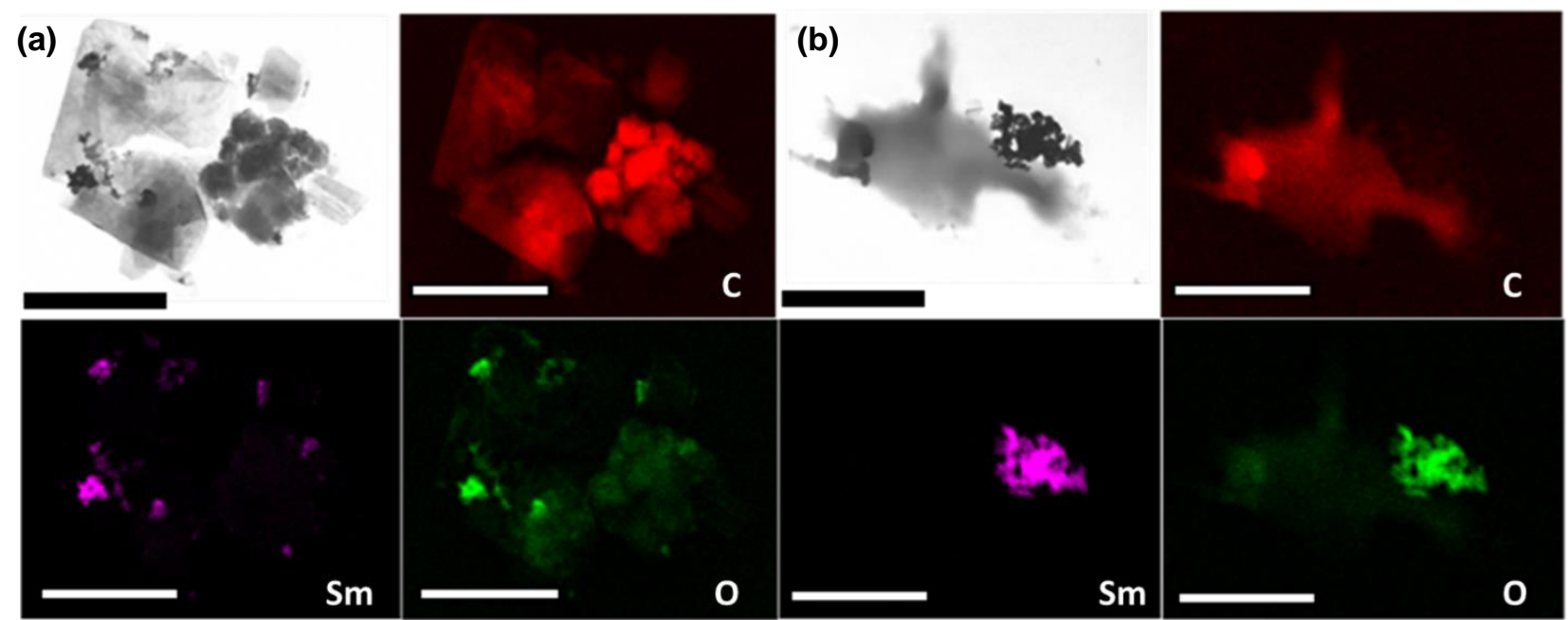

Figure S4. (a) and (b) EDS mapping of as-prepared $\mathrm{Sm}_{2} \mathrm{O}_{3} / \mathrm{GA}$ catalyst (Scale bar $=1 \mu \mathrm{m}$ ). 
Supporting information 4: XRD spectra of as-prepared reduced graphene oxide(rGO) and graphene acid (GA) samples.

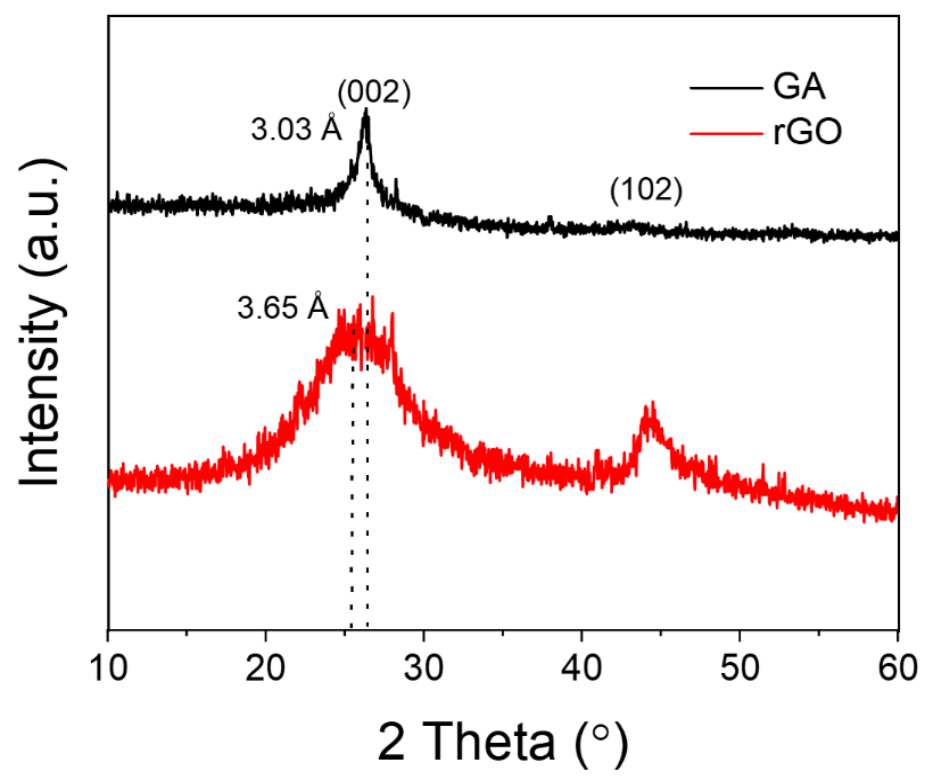

Figure S5. XRD spectra of as-prepared reduced graphene oxide (rGO) and graphene acid (GA) samples showing (002) diffraction plane at $25.2^{\circ}$, which further shifted to $26.4^{\circ}$ in case of graphene acid. The other peak at $2 \theta\left(44.4^{\circ}\right)$ is related to the (102) plane.

\section{Calculation of the interlayer spacing.}

The interlayer spacing can be calculated using the Bragg's law given by the equation:

$$
\lambda=2 \mathrm{~d} \sin (\theta)
$$

where $\lambda$ refers to wavelength of the X-ray beam $(0.154 \mathrm{~nm}), \mathrm{d}$ is the distance between the adjacent sheets or layers, $\theta$ is the diffraction angle.

The interplanar spacing of GA is lower than that of $\mathrm{rGO}$, as indicated by the shift in the (002) peak in the XRD spectrum. The decrease in interplanar spacing in GA could be due to the complete conversion in epoxides and $\mathrm{OH}$ groups. 
Supporting information 5: High Resolution-XPS study of $\mathrm{Sm}_{2} \mathrm{O}_{3} /$ GA heterostructure.
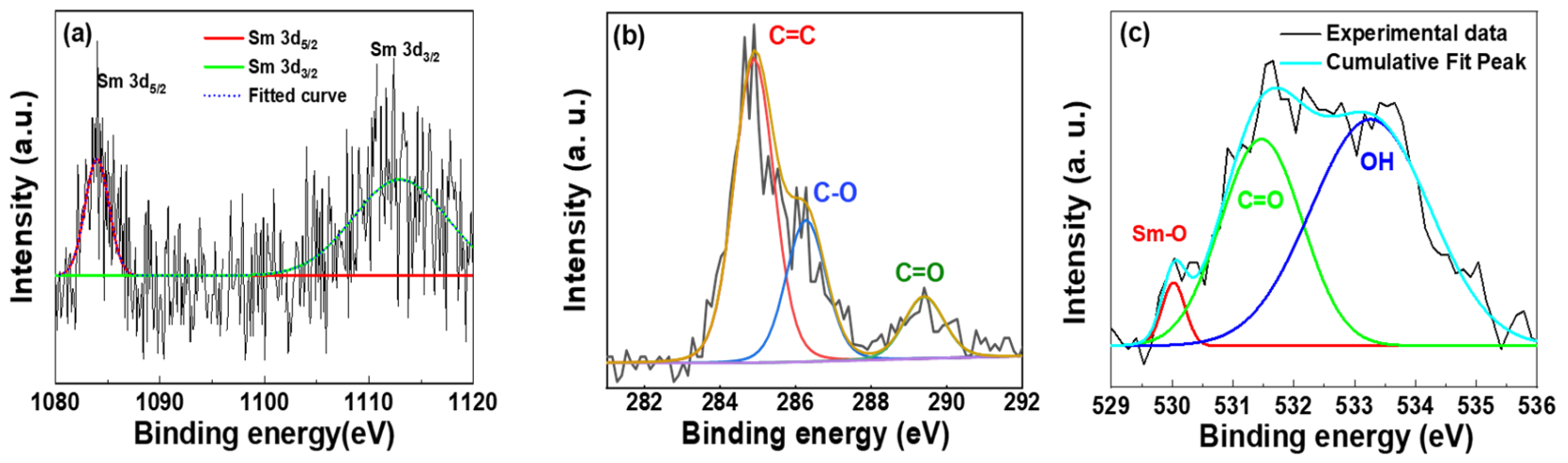

Figure S6. High-resolution XPS spectrum of (a) Sm 3d, (b) C 1s, and (c) 0 1s of the as prepared $\mathrm{Sm}_{2} \mathrm{O}_{3} / \mathrm{GA}$ heterostructure. 
Supporting information 6: Raman spectrum of the $\mathrm{Sm}_{2} \mathrm{O}_{3} / \mathrm{GA}$ Heterostructure.

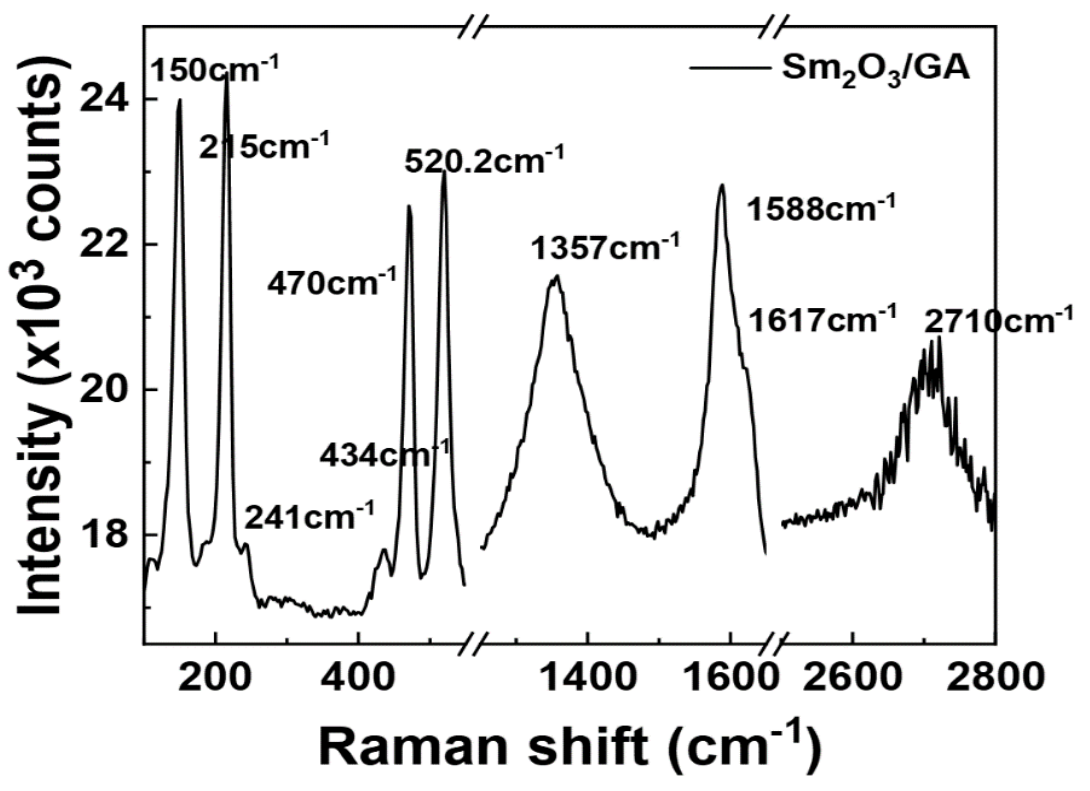

Figure S7. Raman spectrum of $\mathrm{Sm}_{2} \mathrm{O}_{3} / \mathrm{GA}$ catalyst. 

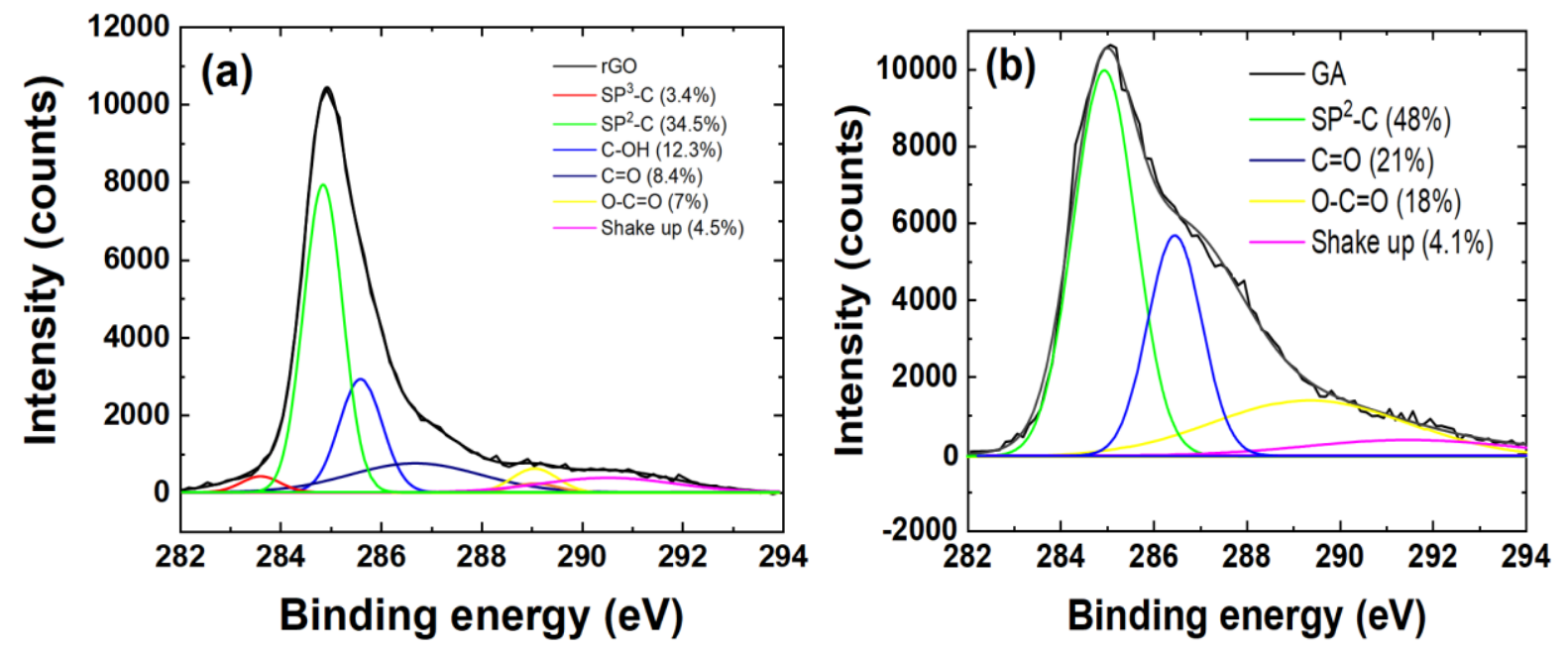

Figure S8. High-resolution XPS spectrum of C 1s (a) rGO and (b) GA.

Table S1. XPS quantification results of $\mathrm{sp}^{2}$ content and -COO groups estimated using $\mathrm{C} 1 \mathrm{~s}$ spectrum of the as-prepared rGO and GA samples.

\begin{tabular}{|l|l|l|}
\hline Sample & $\mathbf{C}=\mathbf{C}$ & -COO \\
\hline rGO & $34.5 \%$ & $7 \%$ \\
\hline GA & $48 \%$ & $18 \%$ \\
\hline
\end{tabular}


Supporting information 7: Raman study of the $\mathrm{Sm}_{2} \mathrm{O}_{3} / \mathrm{GA}$ Heterostructure.

Raman spectroscopy is typically used to characterize graphene by estimating domain sizes and defect densities using the peak intensities of the G- and D-bands. Carrier density, Fermi energy, and strain have also been calculated using peak shifts in Raman spectra. An increase in carrier mobility characterized by a decrease in the full width at half maximum (FWHM) of the 2D-band peak in Raman signals has been reported; however, origins of the phenomenon are not yet fully understood.3,4

Crystal size (La) can be calculated using the following equation.

$$
L_{a}=\frac{I_{D}}{I_{G}}=\frac{C_{\lambda}}{I_{a}}
$$

Where $I_{D}$ and $I_{G}$ refer to (D) band and (G) band intensity respectively. $I_{(D)}$ increase if the contributions from different defects add up independently. $\lambda$ is the Raman excitation wavelength and $C(\lambda)=102$ $\mathrm{nm}^{2}$, for $\lambda=514 \mathrm{~nm}$.

$$
L_{D}^{2}(n m)^{2}=\frac{4.3 \times 10^{3}}{E_{L}^{4}\left(e V^{4}\right)}=\left[\frac{I_{(D)}}{I_{(G)}}\right]^{-1}
$$

Where $E_{\mathrm{L}}=\hbar \omega_{\mathrm{L}}$ is the laser excitation energy in $\mathrm{eV}$. In terms of defect density. Defect density $\left(\mathrm{n}_{\mathrm{D}}\right)$ can be calculated using the following equation.

$$
n_{D}^{2}(\mathrm{~cm})^{-2}=7.3 \times 10^{-9} E_{L}^{4}\left(\mathrm{eV}^{4}\right) \frac{I_{(D)}}{I_{(G)}}
$$

\begin{tabular}{|c|c|c|c|c|c|c|c|c|c|c|c|}
\hline Sample & $\begin{array}{c}D \\
\left(\mathbf{c m}^{-1}\right)\end{array}$ & $\begin{array}{c}\text { G } \\
\left(\mathrm{cm}^{-1}\right)\end{array}$ & $\begin{array}{c}2 \mathrm{D} \\
\left(\mathrm{cm}^{-1}\right)\end{array}$ & $\mathbf{I}_{\mathbf{D}}$ & $\mathbf{I}_{\mathbf{G}}$ & $\mathbf{I}_{\mathbf{D}} / \mathbf{I}_{\mathbf{G}}$ & $\mathbf{I}_{2 \mathrm{D}}$ & $\mathbf{I}_{2 \mathrm{D}} / \mathbf{I}_{\mathbf{D}}$ & $\begin{array}{c}\text { Ld } \\
(\mathbf{n m})\end{array}$ & $\mathrm{n}^{2}\left(\mathrm{~cm}^{-2}\right)$ & $\mathbf{L}_{\mathrm{a}}(\mathrm{nm})$ \\
\hline rGO & 1351 & 1578 & 2700 & 42475 & 44150 & 0.96 & 25475 & 0.6 & 12.3 & $2.16 \times 10^{11}$ & 4.6 \\
\hline GA & 1341 & 1565.5 & 2681 & 7082 & 13857 & 0.21 & 9255 & 1.3 & 26.4 & $4.72 \times 10^{10}$ & 20.9 \\
\hline $\begin{array}{c}\mathrm{Sm}_{2} \mathrm{O}_{3} / \mathrm{G} \\
\mathrm{A}\end{array}$ & 1357.5 & 1588.6 & 2708 & 21575 & 22822 & 0.35 & 20430 & 0.9 & 20.4 & $7.86 \times 10^{10}$ & 12.6 \\
\hline
\end{tabular}

Table S2. Raman study data

\section{Supporting information 8: 2-point probe station conductivity measurements.}

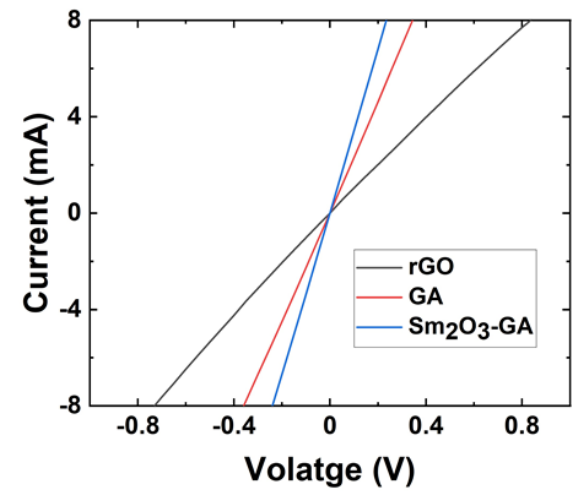

Figure S9. 2-point probe conductivity measurements of $\mathrm{rGO}, \mathrm{GA}, \mathrm{Sm}_{2} \mathrm{O}_{3}(25 \mathrm{ppm}) / \mathrm{GA}$ samples. 
Supporting information 9: Electrochemical characterization of glucose oxidation.
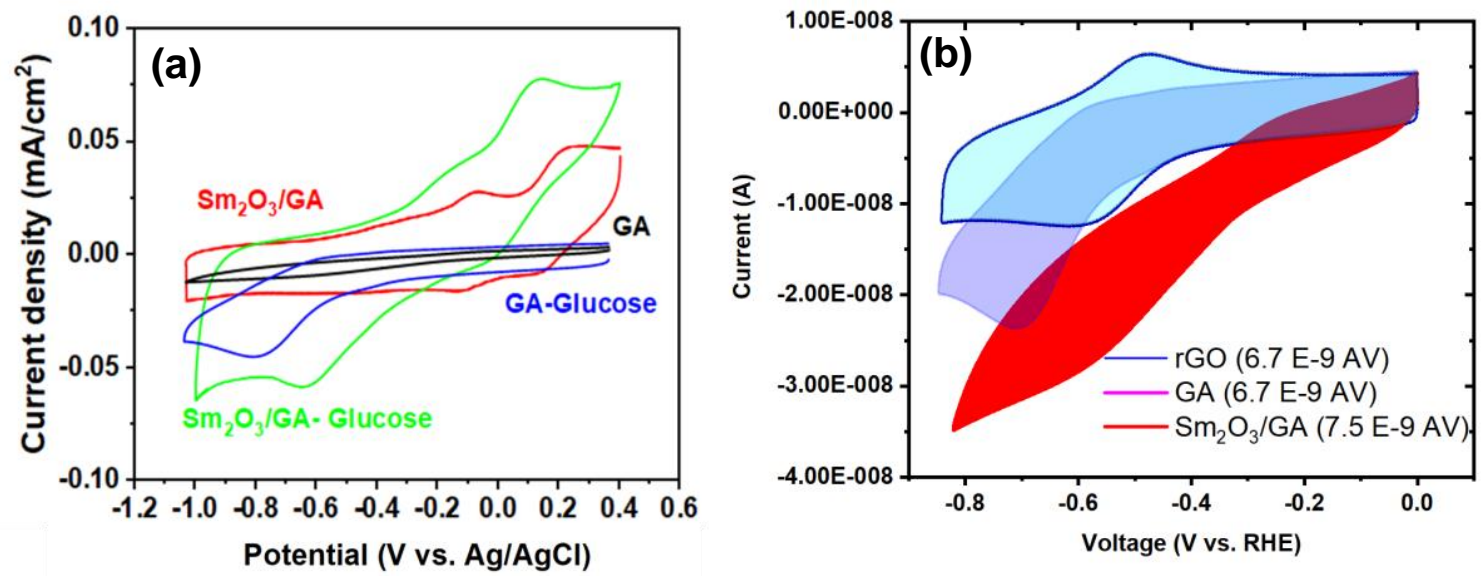

Figure S10. (a) Cyclic voltammetry of GA (Black: in the absence of Glucose, and Blue: in the presence of Glucose) and cyclic voltammetry of $\mathrm{Sm}_{2} \mathrm{O}_{3} / \mathrm{GA}$ (Red: in the absence of Glucose, and Green: in the presence of Glucose); (b) Highlighted cyclic voltammetry of rGO, GA and $\mathrm{Sm}_{2} \mathrm{O}_{3} / \mathrm{GA}$ using potential window $(0.82 \mathrm{~V})$.

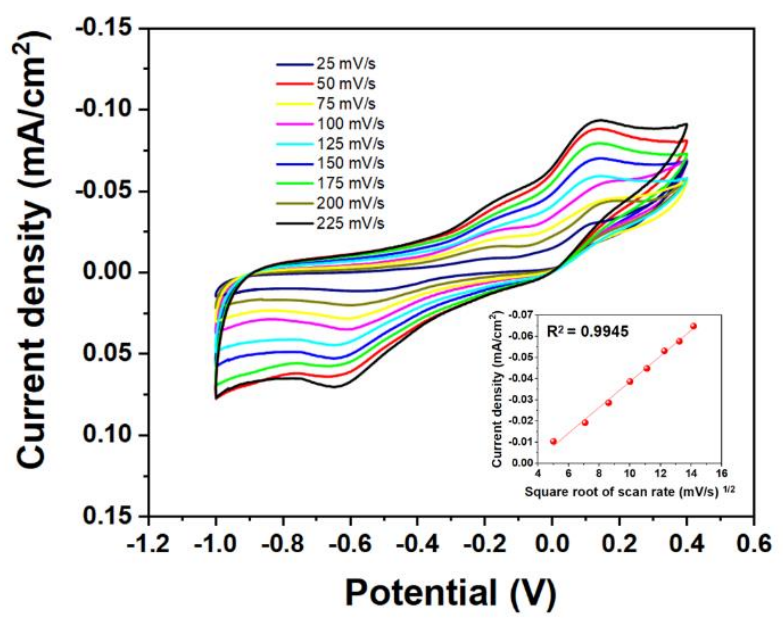

Figure S11. Scan rate effect study over the performance of the $\mathrm{Sm}_{2} \mathrm{O}_{3} / \mathrm{GA}$ for Glucose biosensing; (Inset) A linear relationship between Square root of the scan rate and the current. 


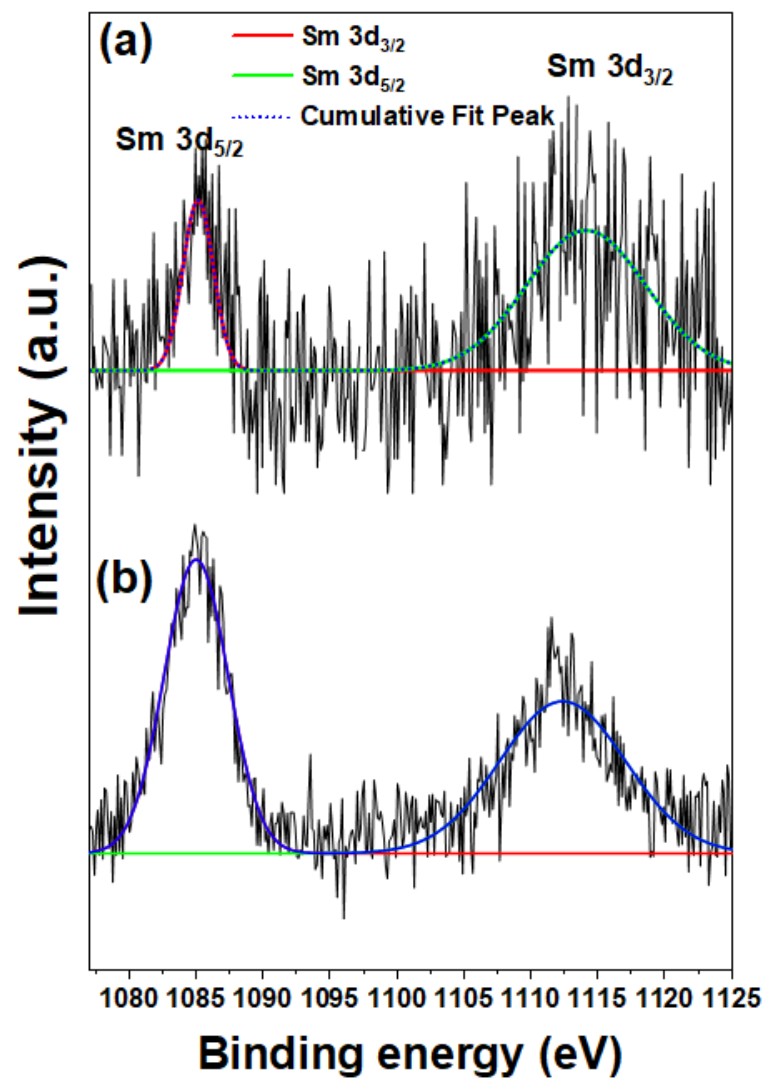

Figure S12. High resolution XPS spectra of $\mathrm{Sm} 3 \mathrm{~d}$ in $\mathrm{Sm}_{2} \mathrm{O}_{3} / \mathrm{GA}$ sample: (a) before and (b) after the electrocatalytic reaction. 
Supporting information 10: ${ }^{13} \mathrm{C}-\mathrm{NMR}$ characterization of the glucose oxidation to Gluconolactone.

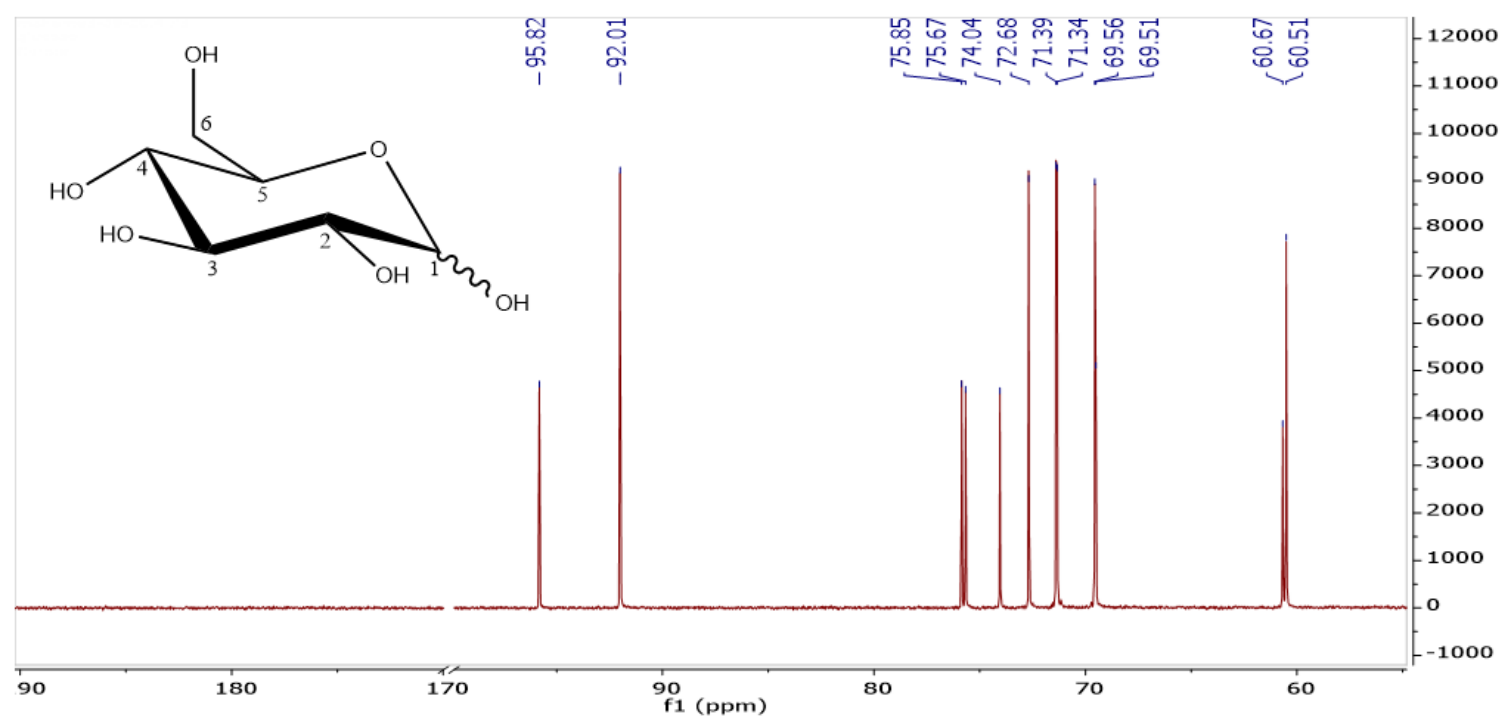

Figure S13. ${ }^{13} \mathrm{C}-\mathrm{NMR}$ of glucose.

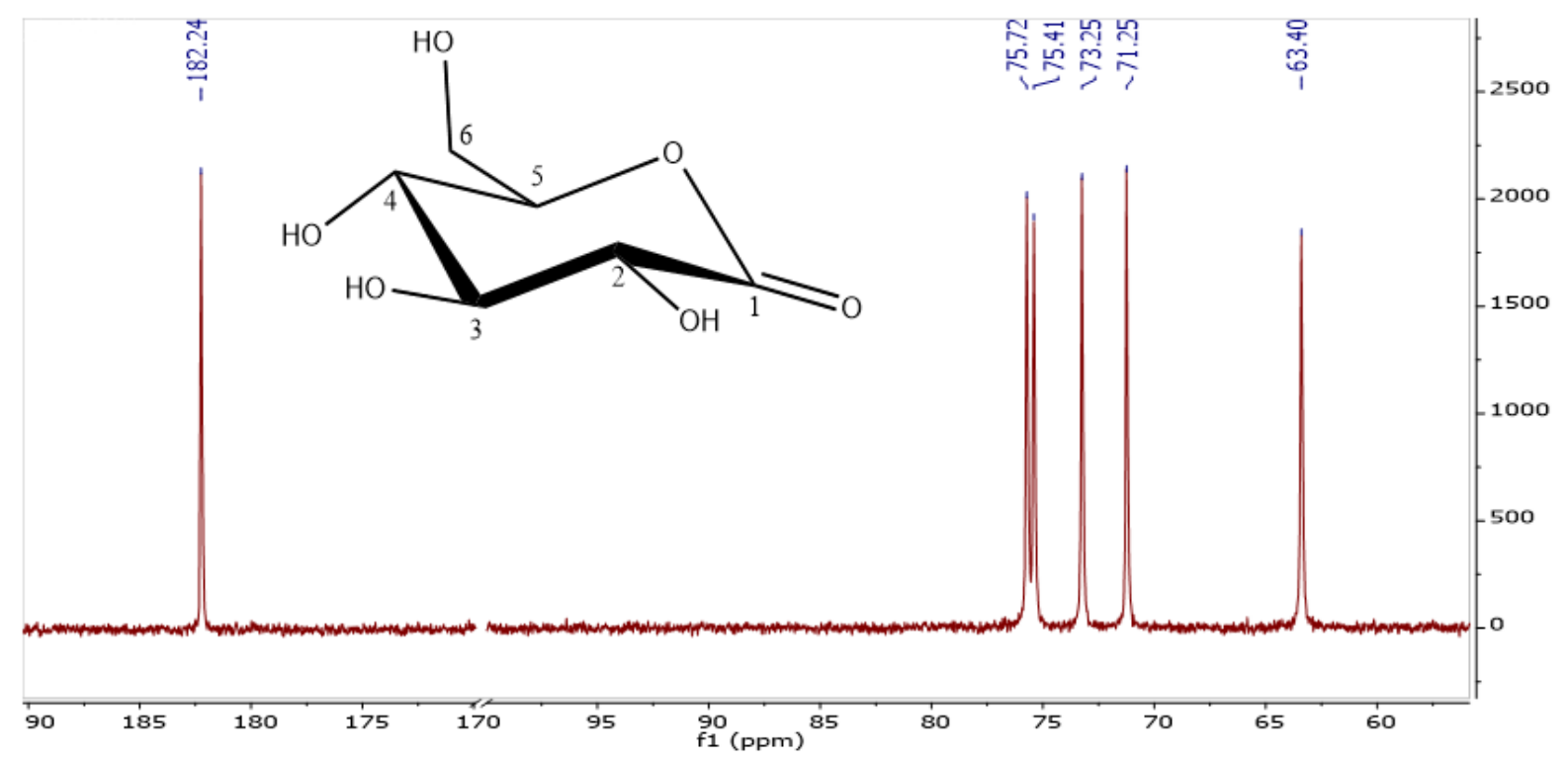

Figure S14. ${ }^{13} \mathrm{C}-\mathrm{NMR}$ of gluconolactone. 
Table S3. ${ }^{13} \mathrm{C}-\mathrm{NMR}$ assignments for both Glucose and Gluconolactone

\begin{tabular}{|c|c|c|c|}
\hline $\begin{array}{l}\text { Chemical } \\
\text { Shift (ppm) }\end{array}$ & $\begin{array}{c}\text { (Glucose) } \\
\text { Assignment }\end{array}$ & $\begin{array}{l}\text { Chemical Shift } \\
\text { (ppm) }\end{array}$ & $\begin{array}{c}\text { (Gluconolactone) } \\
\text { Assignment }\end{array}$ \\
\hline 60.51 & \multirow{2}{*}{ C6 } & \multirow{2}{*}{63.40} & \multirow{2}{*}{$\mathrm{C} 6$} \\
\hline 60.67 & & & \\
\hline 69.51 & \multirow{2}{*}{ C4 } & \multirow{2}{*}{71.25} & \multirow{2}{*}{$\mathrm{C} 2$} \\
\hline 69.56 & & & \\
\hline 71.34 & \multirow{2}{*}{$\mathrm{C} 2$} & \multirow{2}{*}{73.25} & \multirow{2}{*}{ C5 } \\
\hline 71.39 & & & \\
\hline 72.68 & \multirow{2}{*}{$\mathrm{C} 3$} & \multirow{2}{*}{75.41} & \multirow{2}{*}{ C4 } \\
\hline 74.04 & & & \\
\hline 75.67 & \multirow{2}{*}{ C5 } & \multirow{2}{*}{75.72} & \multirow{2}{*}{ C3 } \\
\hline 75.85 & & & \\
\hline 92.01 & \multirow{2}{*}{$\mathrm{C} 1$} & \multirow{2}{*}{182.24} & \multirow{2}{*}{$\mathrm{C} 1$} \\
\hline 95.82 & & & \\
\hline
\end{tabular}

\section{Experimental procedure for the NMR detection of Glucose/Gluconolactone conversion:}

First, we conducted glucose oxidation using $\mathrm{Sm}_{2} \mathrm{O}_{3} / \mathrm{GA}$ modified working electrode with $10 \mathrm{mM}$ of glucose. After $12 \mathrm{~h}$, the electrolyte was collected and lyophilized using a Labconco lyophilizer. This sample was used for NMR characterization to confirm the presence of gluconolactone in the reaction product. It is known that the glucose-gluconolactone conversion occurs via oxidation in the hydroxyl group positioned in the anomeric carbon of glucose which generates a carbonyl group. Hence the change of the anomeric carbon was investigated.

For NMR characterization, we tested two samples which include a test sample (the electrolyte after glucose oxidation) and a control sample (initial glucose sample). The test sample was prepared by dissolving the lyophilized powder obtained after the glucose oxidation study in $600 \mu \mathrm{L}$ of DMSO-d6. The control sample was prepared with $10 \mathrm{mM}$ of D (+)-glucose dissolved in $600 \mu \mathrm{L}$ of DMSO-d6. The ${ }^{13} \mathrm{C}-\mathrm{NMR}$ experiments were performed using Bruker Avance III HD $400 \mathrm{MHz}$ NMR spectrometer equipped with a broadband probe.

The ${ }^{13} \mathrm{C}$-NMR results for the control sample and test sample are shown in Figures S13 and S14, respectively. As shown in Figure S13, in the case of control sample (i.e., glucose), we observed the anomeric carbon peaks located at 92.01 and $95.82 \mathrm{ppm}$ corresponding to the two different enantiomers $\alpha$, $\beta$-Glucose. ${ }^{56}$ As shown in Figure S14, the ${ }^{13} \mathrm{C}$-NMR spectrum of the product from the electrolyte (i.e., reaction product) showed a carbonyl signal located in a shallow field zone (182.24 $\mathrm{ppm}$ ) and matched with the gluconolactone structure, indicating the formation of gluconolactone.7, 8 Moreover, no peaks were observed at 92.01 and $95.82 \mathrm{ppm}$ (corresponding to $\alpha, \beta$-Glucose), confirming the complete oxidation of glucose. Hence, the NMR results confirm the electrocatalytic oxidation of glucose to gluconolactone. 
Supporting information 11: EIS study $\mathrm{Sm}_{2} \mathrm{O}_{3} / \mathrm{GA}$ with different $\mathrm{Sm}_{2} \mathrm{O}_{3}$ loading.

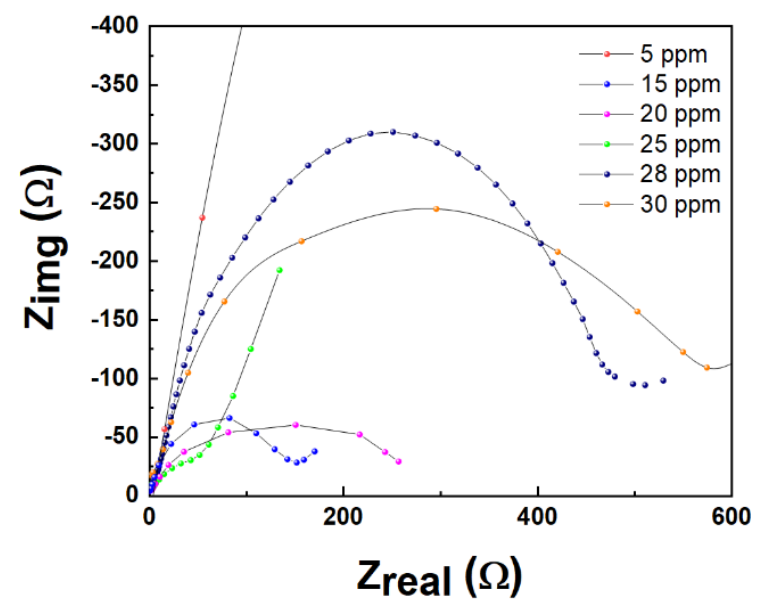

Figure S15. EIS data for loading ratios 5, 15, 20, 25, 28 and 30 ppm of $\mathrm{Sm}_{2} \mathrm{O}_{3}$ over GA samples.

Table S4. EIS fitting parameters of $\mathrm{rGO}, \mathrm{GA}$, and $\mathrm{Sm}_{2} \mathrm{O}_{3} / \mathrm{GA}(25 \mathrm{ppm})$ samples

\begin{tabular}{|c|c|c|c|}
\hline Parameters & rGO & GA & Sm $_{\mathbf{2}} \mathbf{O}_{\mathbf{3}} / \mathbf{G A}$ \\
\hline Rs $(\Omega)$ & 46.51 & 98.41 & 52 \\
\hline CPE1-T & $5.4774 \mathrm{E}-5$ & $6.9565 \mathrm{E}-5$ & 0.0004381 \\
\hline CPE1-P & 0.33 & 0.5166 & 0.465 \\
\hline $\mathrm{R}_{\mathrm{ct}}(\Omega)$ & 784 & 98.32 & 88 \\
\hline $\mathrm{W}_{\mathrm{R}}(\Omega)$ & 1003 & 4355 & 625 \\
\hline $\mathrm{W}_{\mathrm{T}}$ & $4.8894 \mathrm{E}-5$ & 0.098434 & 0.058115 \\
\hline $\mathrm{W}_{\mathrm{P}}$ & 0.55683 & 0.51 & 0.45 \\
\hline
\end{tabular}


Supporting information 12: ECSA study of the as prepared electrocatalysts.
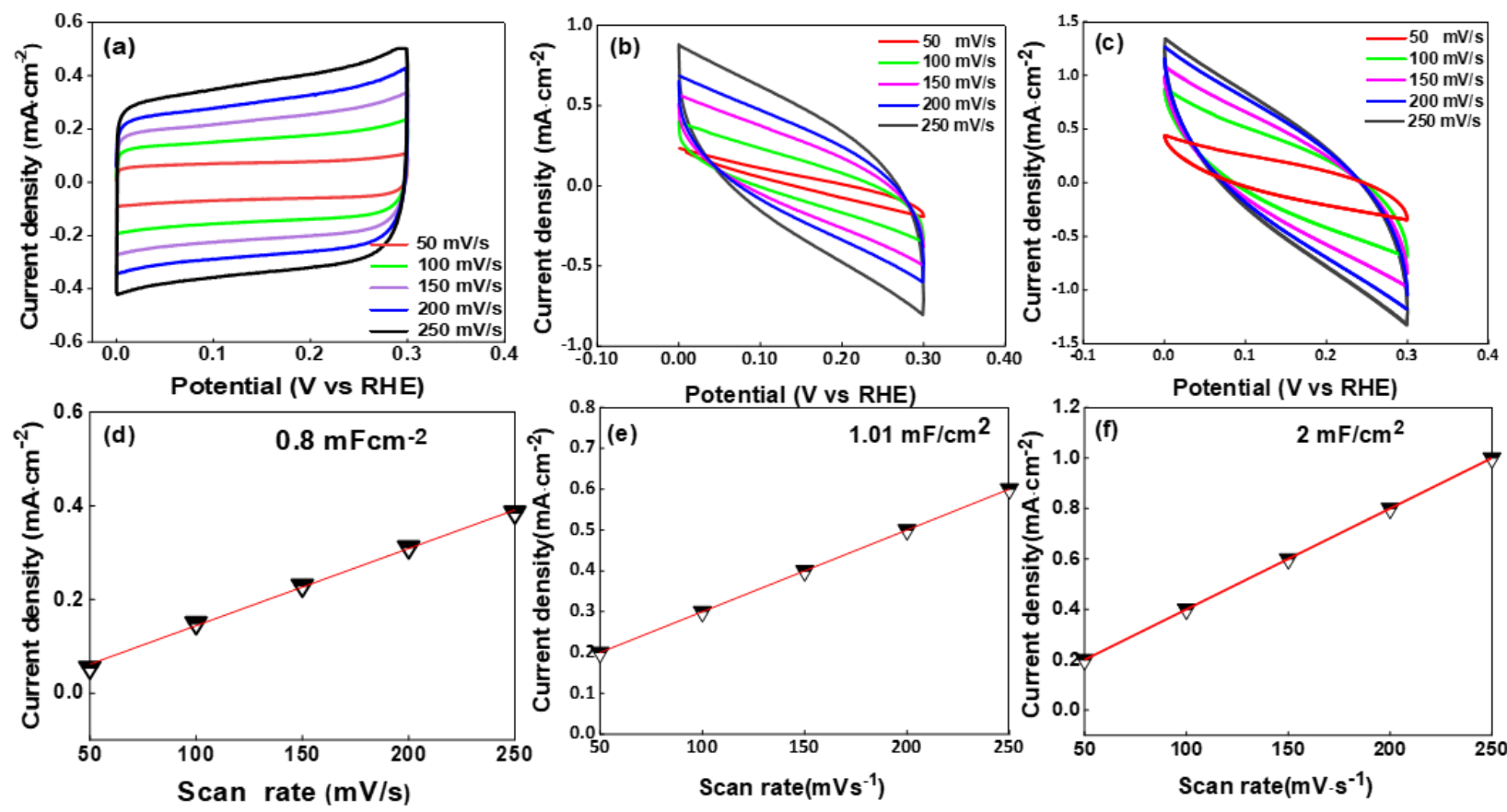

Figure S16. Double layer capacitance in the non-faradaic zone measurements of the as prepared electrocatalysts; (a, d) rGO; (b, e) GA and (c, f) $\mathrm{Sm}_{2} \mathrm{O}_{3} / \mathrm{GA}$.

\subsection{Estimation of Electrochemical Surface Area (ECSA) and Active Site Density.}

Mass specific active site density $\left(S D_{m}\right)$ can be calculated using the following formula.

$$
S D_{m}\left(\text { active site }^{-1}\right)=\frac{\text { integrated } C V \text { area }(A V) \times N_{A}}{n \times \text { scan rate }\left(\frac{V}{S}\right) \times F\left(\frac{C}{m o l}\right) \times m(g)}
$$

$\mathrm{N}$ is the number of atoms per mole, Avogadro number $\left(6.023 \times 10^{23}\right), \mathrm{n}$ is the number of electrons, $\mathrm{F}$ is the Faraday constant $\left(96485 \mathrm{C} \mathrm{mol}^{-1}\right)$, and $\mathrm{m}$ is the electrocatalyst loading $(0.001 \mathrm{~g})$ on glassy carbon electrodes.

\subsection{Specific capacitance calculations}

By assimilating the entire CV area, the specific capacitance (Cs) of one electrode can be measured using:

$$
C s=\frac{\int \mathrm{ivdv}}{2 \times v \times m \times \Delta V}
$$


Where $\int$ ivdv is the area of the CV loop, $v$ is the voltage scan rate, $\mathrm{m}$ is the electrocatalyst mass, and $\Delta \mathrm{V}$ is the potential window.

\subsection{Electrochemical active surface area.}

Electrochemical capacitance measurements were used to determine the active surface area of each catalyst. To measure the electrochemical capacitance, the potential was swept between 0.10 to $0.30 \mathrm{~V}$ vs RHE five times at each of eleven different scan rates (50 to $250 \mathrm{mV} / \mathrm{s}$ ) (Figure S16). We measured the capacitive currents in a potential range where no faradic processes are observed, i.e., at $0.20 \mathrm{~V}$ vs. RHE. The measured capacitive currents are plotted as a function of scan rate, and a linear fit is determined. Specific capacitance can be measured using the area of the cyclic voltammetry in the alkaline medium as shown in Figure S10b. The calculated ECSA values are illustrated in Table S2.

$$
A_{E C S A}^{W E}=\frac{C_{d l}}{C_{s}}
$$

Table S5. Active site density, specific capacitance, and electrochemical surface area (ECSA) of the catalysts estimated from cyclic voltammograms (CV) measurements

\begin{tabular}{|c|c|c|c|c|}
\hline Sample & \# of active sites/g & $C_{s}\left(\mu F \cdot \mathbf{c m}^{-2}\right)$ & $C_{d l}\left(\mu F \cdot \mathrm{cm}^{-2}\right)$ & $\operatorname{ECSA}\left(\mathrm{cm}^{2}\right)$ \\
\hline rGO & $(1.284 \pm 0.1) \times 10^{18}$ & 76 & 800 & 10.5 \\
\hline GA & $(2.221 \pm 0.2) \times 10^{23}$ & 41 & 1100 & 26.8 \\
\hline $\mathrm{Sm}_{2} \mathrm{O}_{3} / \mathrm{GA}$ & $(2.651 \pm 0.2) \times 10^{23}$ & 45.75 & 2000 & 42.4 \\
\hline
\end{tabular}


Supporting information 13: HOMO- LUMO measurements.
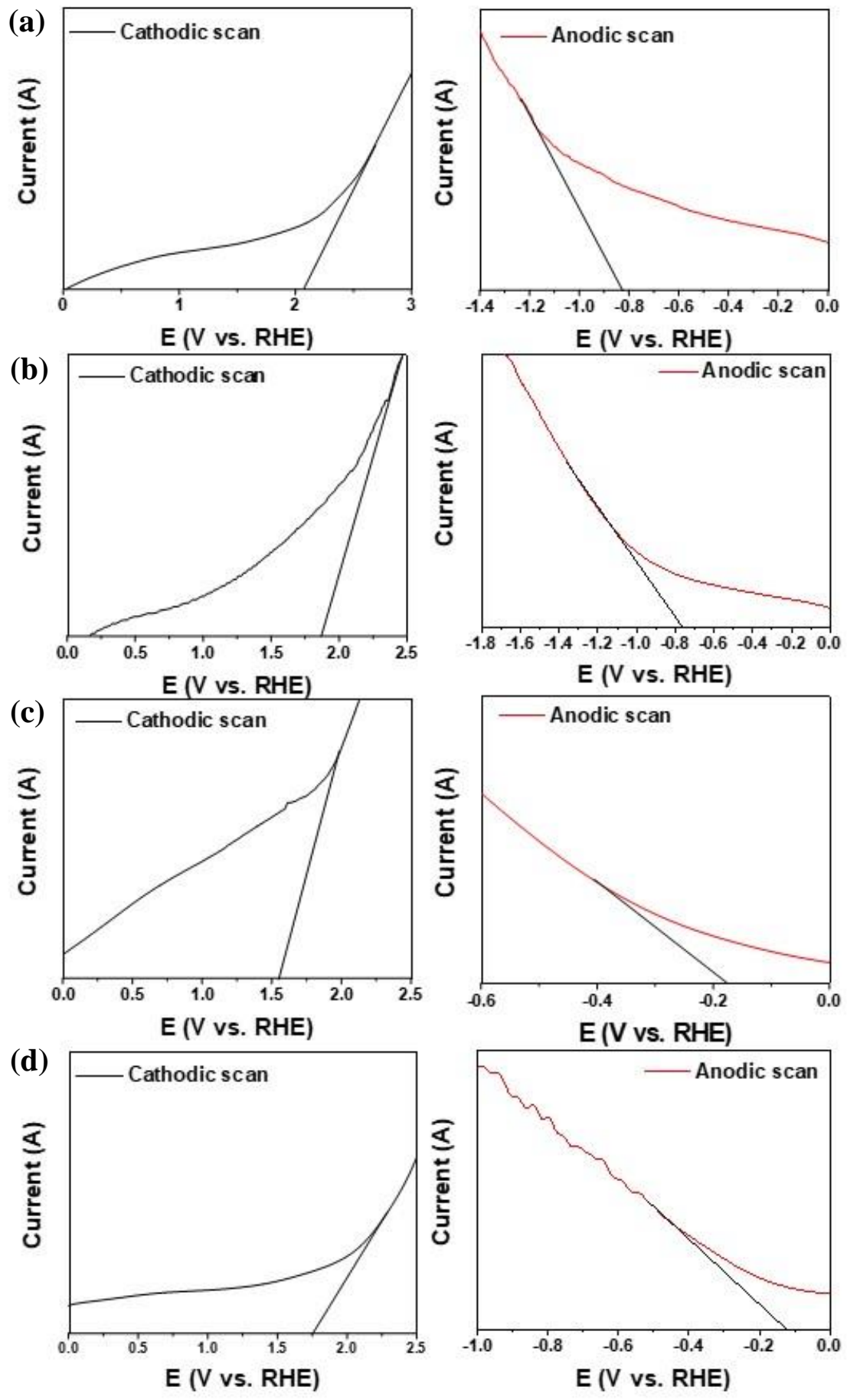

Figure S17. Linear sweep voltammetry measurements for HOMO and LUMO level determination. Anodic scan for determining the valence band maximum at $20 \mathrm{mV} . \mathrm{s}^{-1}$, Cathodic scan for determining the conduction band minimum at $20 \mathrm{mV}^{-1}$ (a-d) $\mathrm{Sm}_{2} \mathrm{O}_{3}, \mathrm{rGO}$, GA and GA/ $\mathrm{Sm}_{2} \mathrm{O}_{3}$ respectively. 
Supporting information 14: DFT calculations.

11.1. Density Functional Theory (DFT) based calculations were carried out using Cambridge sequential total energy package (CASTEP) in Material Studio software. The generalized gradient approximation (GGA) of the Perdew-Burke-Ernzerh (PBE) functional was applied to explain the exchange-correlation interactions. The DFT-D3MOl method was adopted to consider the van der Waals $(\mathrm{vdW})$ interaction. For geometric convergence, the thresholds for energy and force were set to $10^{-5} \mathrm{eV} /$ atom and $0.02 \mathrm{eV} / \AA ̊$, respectively. Cutoff energy of $550 \mathrm{eV}$ was selected for a plane wave basis.

\subsection{Glucose oxidation mechanism}

One electron-based reaction was involved in a glucose oxidation process, which was carried out at the electrocatalyst surface to generate Gluconolactone. From a thermodynamic perspective, the thermodynamic kinetics of the Glucose reactions under alkaline medium conditions are equivalent:

$$
\text { Glucose } \stackrel{\text { Alkaline medium }}{\longrightarrow} \text { Gluconolactone }+e^{-}
$$

The generally accepted reaction mechanism in alkaline medium can be expressed as below:

$$
\begin{aligned}
& \mathrm{OH}+* *(\mathrm{HO})_{2} * \\
& \mathrm{HO}^{*}+\mathrm{OH}^{*} \longrightarrow(\mathrm{HO}) \mathrm{O}^{*}+\mathrm{H}_{2} \mathrm{O} \\
& (\mathrm{HO}) \mathrm{O} * \stackrel{\text { Glucose }}{\longrightarrow}[(\mathrm{HO}) \mathrm{O}]+{ }^{*} \text { Glucose }+\mathrm{e}^{-} \\
& {[(\mathrm{HO}) \mathrm{O}]+{ }^{*} \text { Glucose } \longrightarrow\left[\mathrm{H}_{2} \mathrm{O}\right] * \text { Glucose }} \\
& {\left[\mathrm{H}_{2} \mathrm{O}\right]{ }^{*} \text { Glucose } \longrightarrow \text { Gluconolactone }+\mathrm{H}_{2} \mathrm{O}+\mathrm{e}^{-}}
\end{aligned}
$$

The $(*)$ refers to the active sites on the catalyst surface. Oxidation kinetics and intrinsic electrocatalytic bio-sensing activity of a given electrocatalyst can be studied in terms of the Gibbs free energy changes $(\Delta \mathrm{G})$ during the electrochemical reaction process ${ }^{9,10}$. Under Alkaline conditions, the equations of free energy $\Delta G$ for the one electron-proton-coupled transport, which can be expressed as:

$$
\Delta \mathrm{G}_{1}=\Delta \mathrm{G}(\mathrm{HO})_{2} *-\Delta \mathrm{G} \mathrm{OH}--\mathrm{eU}+\mathrm{KBT} \ln (10) \mathrm{pH}
$$


$\Delta \mathrm{G}_{2}=\Delta \mathrm{G}(\mathrm{HO}) \mathrm{O} *-\Delta \mathrm{GHO}{ }^{*}-\mathrm{eU}+\mathrm{KBT} \ln (10) \mathrm{pH}$

$\Delta \mathrm{G}_{3}=\Delta \mathrm{G}[(\mathrm{HO}) \mathrm{O}]+{ }^{*} \mathrm{Glucose}-\Delta \mathrm{G}(\mathrm{HO}) \mathrm{O}^{*}-\mathrm{eU}+\mathrm{KBT} \ln (10) \mathrm{pH}$

$\Delta \mathrm{G}_{4}=\Delta \mathrm{G}\left[\mathrm{H}_{2} \mathrm{O}\right] * \mathrm{Glucose}-\Delta \mathrm{G}[(\mathrm{HO}) \mathrm{O}]+{ }^{*} \mathrm{Glucose}-\mathrm{eU}+\mathrm{KBT} \ln (10) \mathrm{pH}$

$\Delta \mathrm{G}_{5}=\Delta \mathrm{G}$ Gluconolactone $-\Delta \mathrm{G}\left[\mathrm{H}_{2} \mathrm{O}\right] * \mathrm{Glucose}-\mathrm{eU}+\mathrm{KBT} \ln (10) \mathrm{pH}$

where $\mathrm{eU}$ is the potential against normal $\mathrm{Ag} / \mathrm{AgCl}$ reference electrode (RHE) under ambient conditions, $\mathrm{kBT}^{*} \ln (10) . \mathrm{pH}$ represents the total free energy changes of the proton $(\Delta \mathrm{GH}+(\mathrm{pH}))$ relative to the RHE electrode at nonzero $\mathrm{pH}$. Therefore, the overpotential is readily defined as the $\Delta \mathrm{G}$ of the largest kinetic barrier level at $\mathrm{U}=0$ (E1). For calculating the experimental over potential from a calculation viewpoint, the diagram of $\Delta \mathrm{G}$ at increased $\mathrm{U}(\mathrm{E} 2, \mathrm{E} 3$, and E4) was carried out. The last downward step(slowest) in the $\Delta \mathrm{G}$ at increased applied potential (E3) was defined as the potentialdetermining step, ${ }^{11}$ as illustrated in the following equation:

$$
\eta=\frac{\left[\Delta G_{1,}^{0} \Delta G_{2,}^{0} \Delta G_{3,}^{0} \Delta G_{4,}^{0}\right]}{e}-E^{0}
$$

where $\Delta \mathrm{Gn} 0$ is the $\Delta \mathrm{G}$ at the nth reaction when $\mathrm{U}=0$, in which $\mathrm{n}=1,2,3$, or 4 . 
(a)

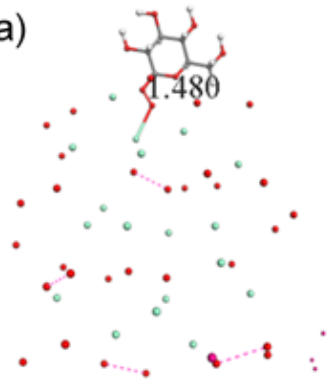

(d)

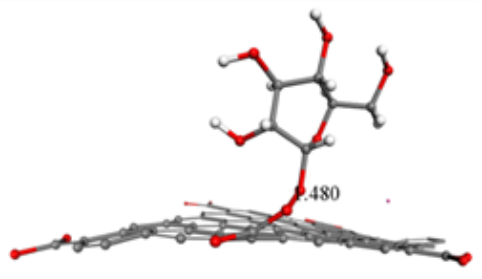

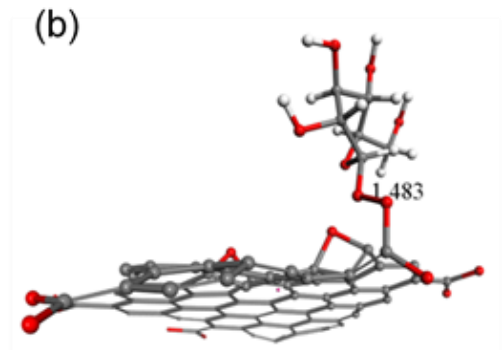

(e)

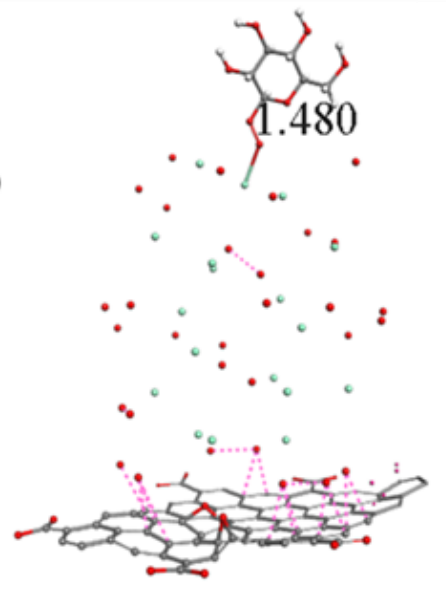

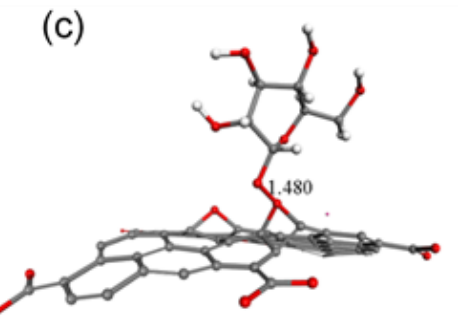

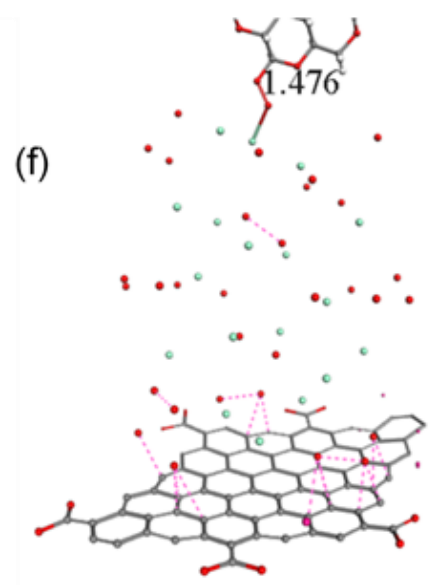

Figure S18. Idealized structures and (O-O) bond length calculations of (a) $\mathrm{Sm}_{2} \mathrm{O}_{3}$-Glucose, (b) rGO(COOH)-Glucose, (c) rGO(COOH), (d) GA(COOH)-Glucose, (e) rGO- $\mathrm{Sm}_{2} \mathrm{O}_{3}$-Glucose and (f) GA$\mathrm{Sm}_{2} \mathrm{O}_{3}$-Glucose( $\mathrm{Red}=0$, White $=\mathrm{H}$, off white=Sm and Gray=Carbon). 
Supporting information 15: Glucose oxidation active sites.
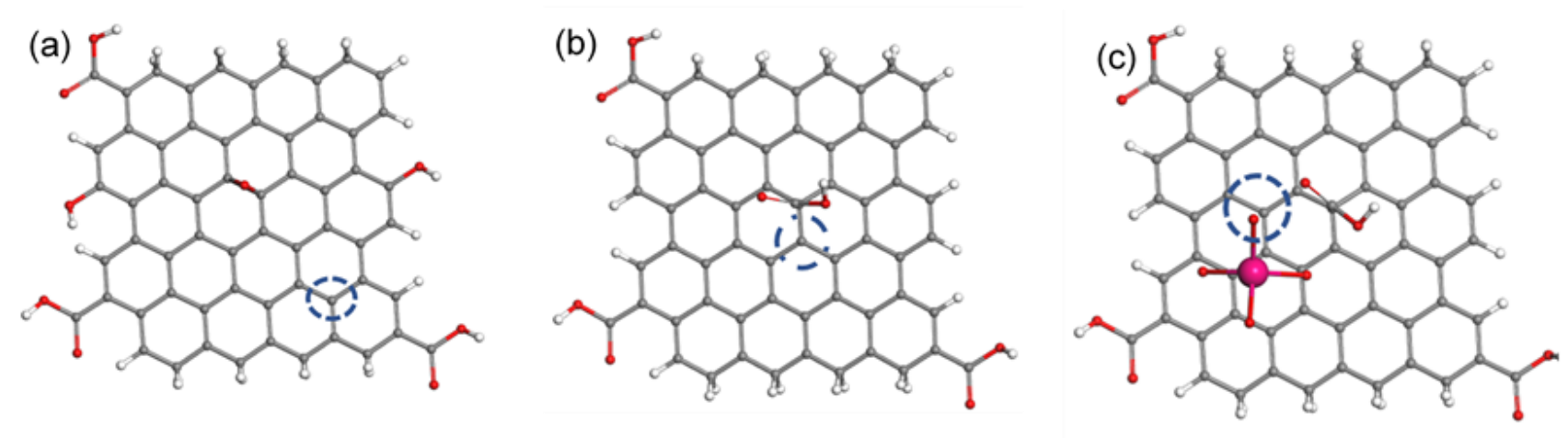

Figure S19. Possible different glucose oxidation adsorption positions of (a) rGO, (b) GA, and (c) $\mathrm{Sm}_{2} \mathrm{O}_{3} /$ GA heterostructure. 
Supporting information 16: Catalyst reusability and stability
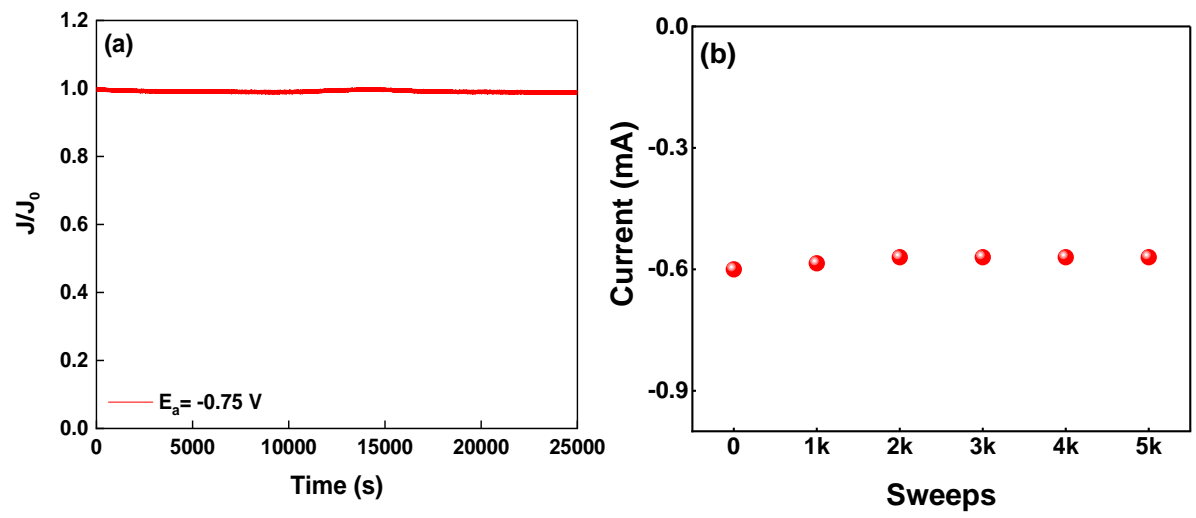

Figure S20. (a) Chronoamperometric stability test of the materials in alkaline medium and in the presence of $10 \mathrm{mM}$ glucose; (b)Stability of the current response measured under a $10 \mathrm{mM}$ glucose mixture over $5 \mathrm{~K}$ cycles. 
Supporting information 17: Idealized structures and ORR active sites of graphene acid.

(a)

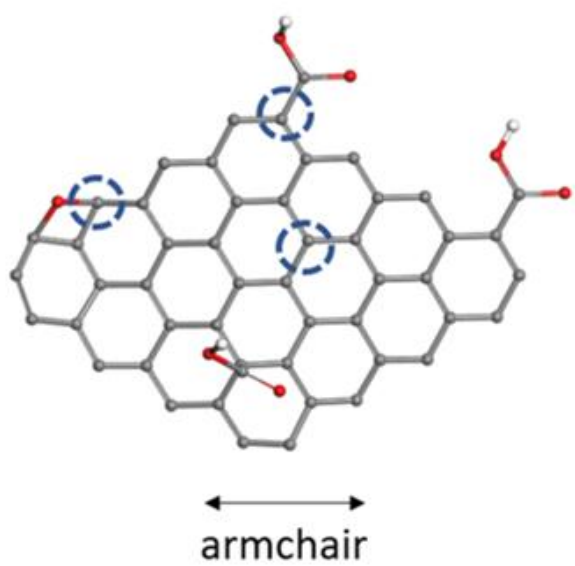

(b)

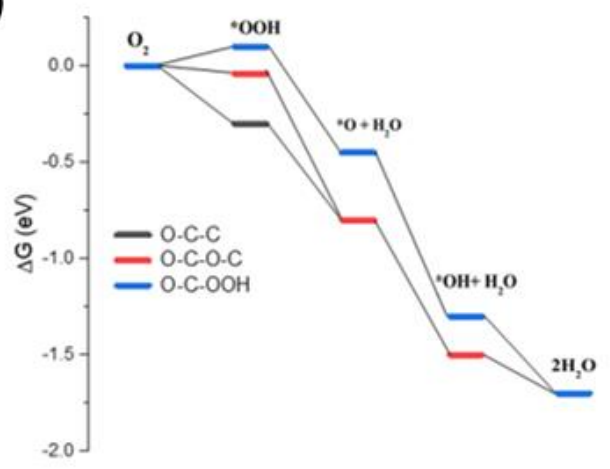

Figure S21. (a) Idealized structure of graphene acid (b) Free energy plot of the ORR mechanism over 3 possible different positions of the structure of graphene acid.

Table S6. Comparison of glucose oxidation performance (both enzymatic and nonenzymatic) of different materials reported in the literature with those used in this present study.

\begin{tabular}{|c|c|c|c|c|}
\hline Sample & LOD (mM) & Range(mM) & Sensitivity $\left(\mu \mathrm{A} . \mathrm{mM}^{-1}\right)$ & Ref \\
\hline $\mathrm{GCE} / \mathrm{PB} / \mathrm{PDA}-\mathrm{GO}_{\mathrm{x}}$ & 0.2 & $0.2-3.4$ & 1.59 & 12 \\
\hline Gr/PANI/AuNPs/GO & 0.2 & $0.2-11.2$ & 4.58 & 13 \\
\hline SPCE/PPy/CNC/GO & 1 & $1.0-20$ & 0.73 & 14 \\
\hline $\mathrm{GO}_{\mathrm{x}} / \mathrm{PMPD}-\mathrm{PB} / \mathrm{GC}$ & $2.5 \times 10^{-2}$ & $2.5 \times 10^{-2}-0.65$ & 2.54 & 15 \\
\hline Cellulose/GO $/$ PB-SPCE & $2.5 \times 10^{-1}$ & $2.5 \times 10^{-1}-2.00$ & 2.14 & 16 \\
\hline GOx/AuPd/PI/RGO & $2.4 \times 10^{-2}$ & $2.4 \times 10^{-2}-4.6$ & 2.82 & 17 \\
\hline $\mathrm{GA}-\mathrm{GO}_{\mathrm{x}} / \mathrm{Pt}$ & $1 e^{-2}$ & $0.01-20$ & 1.47 & 18 \\
\hline GOx/C@ZnO nanowire/Ti & $3 \times 10^{-3}$ & $3 \times 10^{-3}-3.45$ & 23.2 & 19 \\
\hline GR-CNT/ZnO-GO & $4.5 \times 10^{-4}$ & $4.5 \times 10^{-4}-16$ & 21 & 20 \\
\hline $\mathrm{GO}_{\mathrm{x}} / \mathrm{BSA} / \mathrm{Nafion} / \mathrm{ZnO}$ & $2.2 \times 10^{-2}$ & $2.2 \times 10^{-2}-6.5$ & 5.36 & 21 \\
\hline nanoparticle/IL/ESM & $10^{-6}$ & $1 \times 10^{-6}-600$ & - & 22 \\
\hline $\mathrm{GO}_{\mathrm{x}} / \mathrm{Pt}-\mathrm{Pb} / \mathrm{CNTs}$ & $10^{-3}$ & $1 \times 10^{-6}-11$ & 17 & 23 \\
\hline $\mathrm{GO}_{\mathrm{x}} / \mathrm{Cu} / \mathrm{MWCNTs}$ & $2.1 \times 10^{-5}$ & $2.1 \times 10^{-5}-3.6$ & 251.4 & 24 \\
\hline $\mathrm{ZnO}-\mathrm{CuO}$ & - & $1 \times 10^{-6}-10$ & 38.1 & 25 \\
\hline Ni/NiO-rGO-Nafion/SPE & $5.9 \times 10^{-3}$ & $5.9 \times 10^{-3}-15$ & 8.24 & 26 \\
\hline $\mathrm{C@ZnO/GC}$ & $1 \times 10^{-6}$ & $1 \times 10^{-6}-13.8$ & 2.97 & 27 \\
\hline $\mathrm{Ni}_{60} \mathrm{Nb}_{40}$ Nanoglass & $100 \times 10^{-6}$ & $100 \times 10^{-6}-15$ & 20 & 28 \\
\hline $\mathrm{Sm}_{2} \mathrm{O}_{3} / \mathrm{GA}$ & $107 \times 10^{-6}$ & $107 \times 10^{-6}-10$ & 21.7 & This work \\
\hline
\end{tabular}


Supporting information 18: Electrochemical characterization of the GBFC.

We have measured the ORR for the GA system using a rotating desk electrode (RDE) and different rotating speeds, as shown in Figure S22 (a). Furthermore, we have calculated the number of electrons using the Koutecky-Levich (K-L) plot, which was found to be 3.56 electrons, as shown in Figure S22 (b). This confirms that the material tends to go through the 4e pathway ensures favors water as a product. The details for the rotating disc electrode measurement are provided below

\section{Rotating disk electrode}

A glassy carbon disc of $5 \mathrm{~mm}$ in diameter (Pine Instruments Company) was employed as the working electrode for the rotating disc electrode (RDE) measurements. All electrochemical experiments were performed using a potential range from 0.2 to $-0.8 \mathrm{~V} \mathrm{vs}$. $\mathrm{Ag} / \mathrm{AgCl}$ at a scan rate of $10 \mathrm{mV} / \mathrm{s}$ using $\mathrm{NaOH}$ $0.05 \mathrm{M} \mathrm{O}_{2}$ saturated solutions. All potentials were indexed to the RHE. The kinetic parameters were estimated by applying the Koutecky-Levich (K-L) equations.

$$
\begin{gathered}
\frac{1}{j}=\frac{1}{j_{k}}+\frac{1}{j_{l}}=\frac{1}{B \omega^{1 / 2}}+\frac{1}{j_{k}} \\
B=0.62 n F C_{0} D_{0}^{2 / 3} v^{-1 / 6} \\
j_{k}=n F k C_{0}
\end{gathered}
$$

Where $\mathrm{J}$ is the measured current density, $\mathrm{j}_{\mathrm{K}}$ and $\mathrm{j}_{\mathrm{L}}$ are the kinetic and diffusion limiting current densities, respectively, $\omega$ is the electrode rotation rate, $n$ is the overall number of electrons transferred for the oxygen reduction, $\mathrm{F}$ is the Faraday constant, $\mathrm{C}_{0}$ is the bulk concentration of $\mathrm{O}_{2}$ dissolved in the electrolyte $\left(1.22 \times 10^{-6} \mathrm{~mol} \cdot \mathrm{L}^{-1}\right.$ for $\left.0.05 \mathrm{M} \mathrm{NaOH}\right), \mathrm{D}_{0}$ is the diffusion coefficient of $\mathrm{O}_{2}$ $\left(1.9 \times 10^{-5} \mathrm{~cm}^{2} \cdot \mathrm{s}^{-1}\right.$ for $\left.0.05 \mathrm{M} \mathrm{NaOH}\right), \mathrm{v}$ is the kinematic viscosity of the electrolyte $\left(8.7 \times 10^{-3} \mathrm{~cm}^{2}\right.$ $\cdot \mathrm{s}^{-1}$ for $\mathrm{NaOH}$ ). $\mathrm{k}$ is the electron transfer rate constant during ORR. ${ }^{29,} 30$
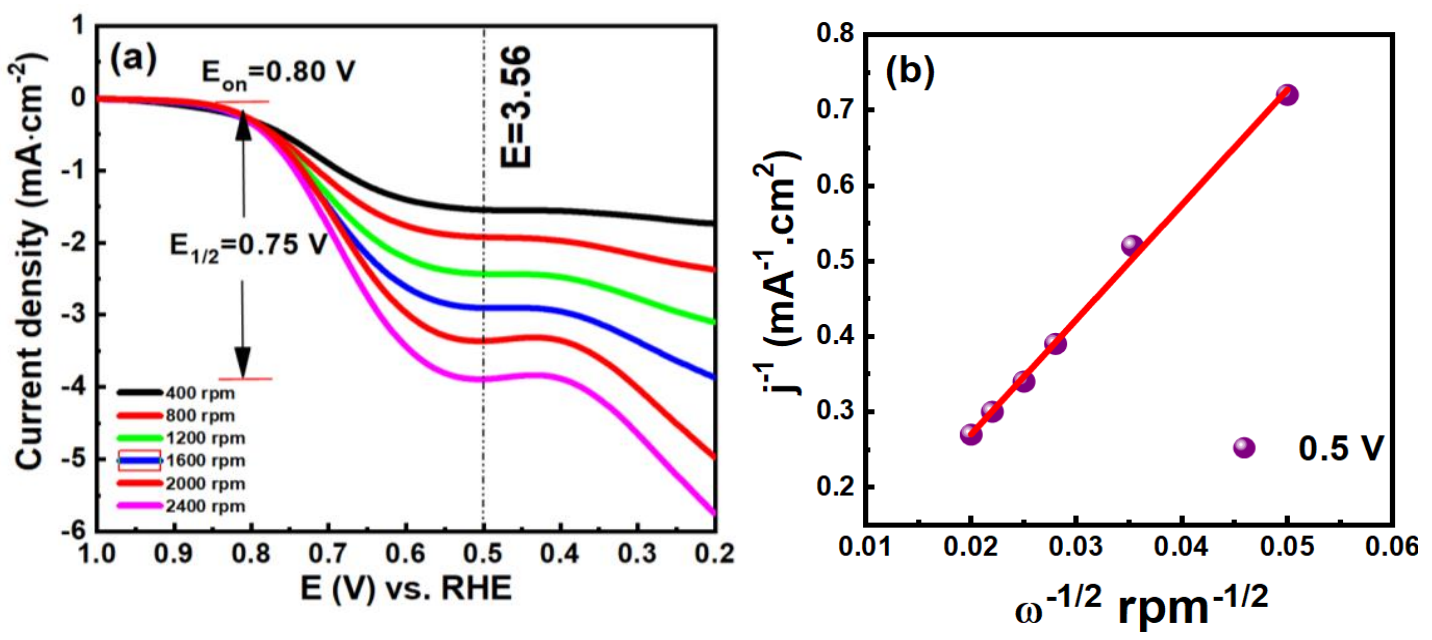

Figure S22. (a) Rotating disk voltammogram (RDV) curves at different rotation rates for GA sample. (b): K-L plots. 


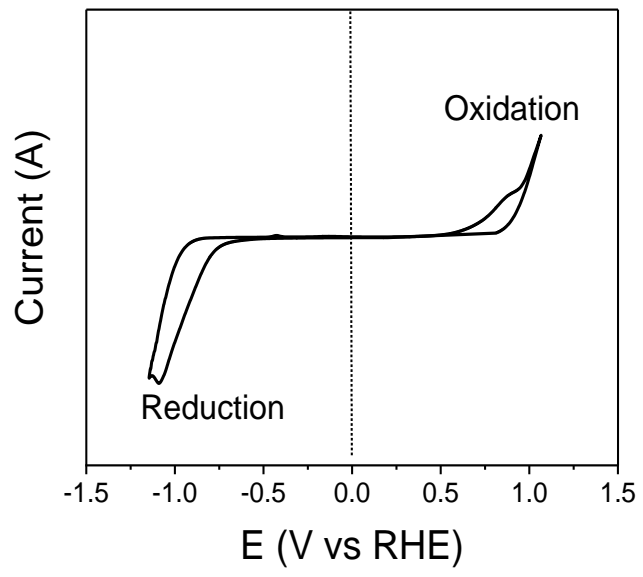

Figure S23. Cyclic voltammogram of the GBFC comprising a $\mathrm{Sm}_{2} \mathrm{O}_{3} / \mathrm{GA}$ heterostructure as an anode, fueled by $30 \mathrm{ml}$ saliva. The scan rate is $5 \mathrm{mV} / \mathrm{s}$. 


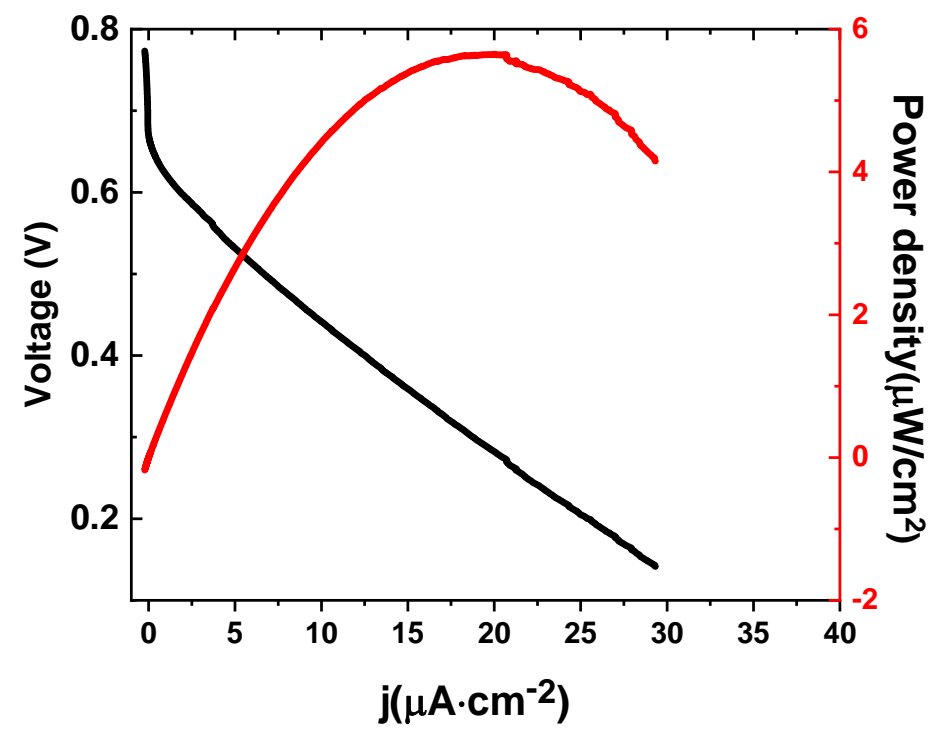

Figure S24. Polarization curves and electrical power density extracted from the biofuel cell (GBFC) using Pt as ORR cathode and Saliva as electrolyte.
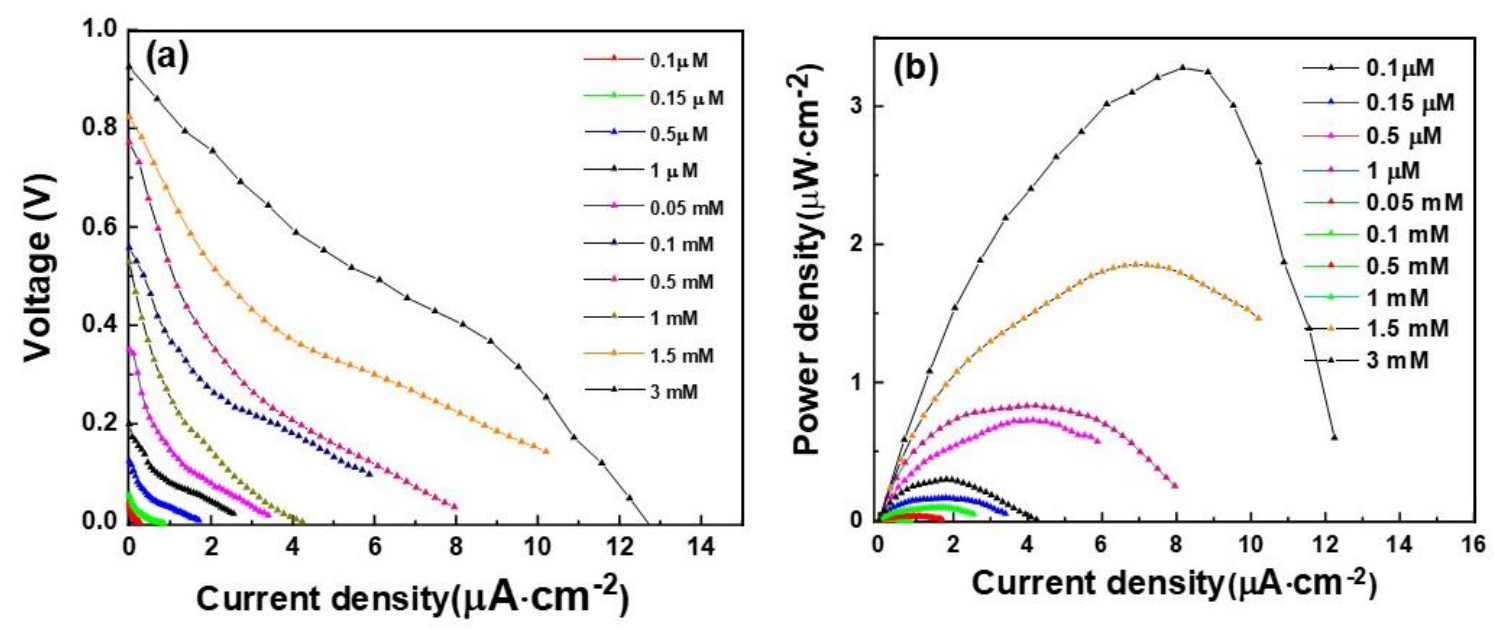

Figure S25. Polarization curves and electrical power density extracted from the biofuel cell (GBFC) using different concentrations $(0.1 \mu \mathrm{M}-3 \mathrm{mM})$ of Glucose in PBS electrolyte. 

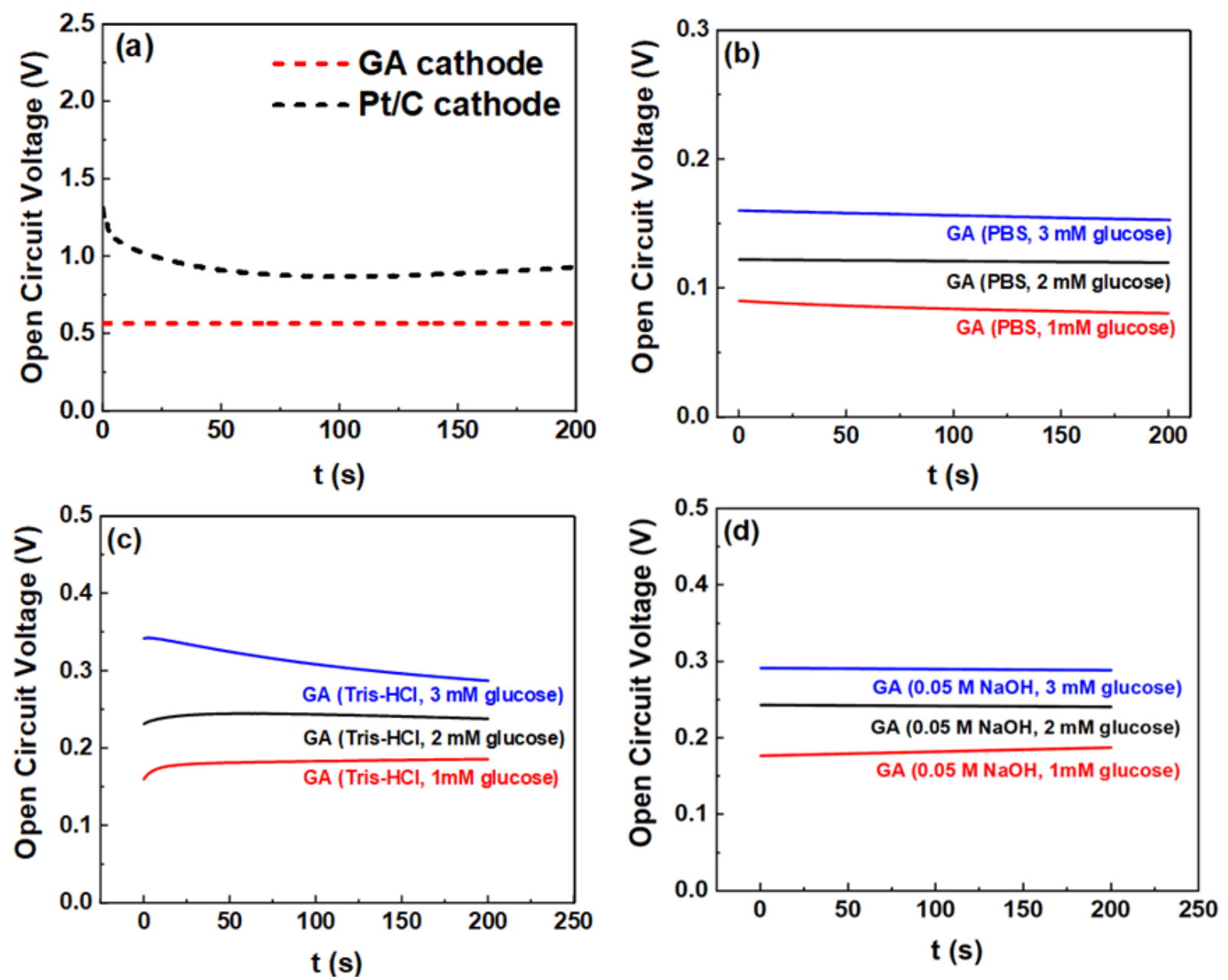

Figure S26. (a) OCV of GBFC using Saliva as electrolyte (Pt/C (black dotted line) and GA (Red dotted line)) as ORR cathode and $\mathrm{Sm}_{2} \mathrm{O}_{3} / \mathrm{GA}$ as Glucose oxidation anode; OCV of GBFC using (b) PBS and (c) Tris- $\mathrm{HCl}$ and (d) $\mathrm{NaOH}$ electrolytes (1, 2- and 3-mM glucose). 
Table S7. Comparison of reported biofuel cell studies with current work

\begin{tabular}{|c|c|c|c|c|c|}
\hline Cathode & Anode & $\begin{array}{c}\text { Electrolyte, } \\
\text { Glucose } \\
\text { concentration }\end{array}$ & $\mathrm{P}\left(\mathrm{mW} \cdot \mathrm{cm}^{-2}\right)$ & $\begin{array}{c}\mathrm{OCV} \\
(\mathrm{V})\end{array}$ & Ref \\
\hline p(EDOT-со-EDOTOH) & P-90/GOx & PBS (10 mM) & $2.5 \times 10^{-3}$ & 0.35 & 31 \\
\hline BOD-CNF & PQQ-sGDH/P024-P195 & PBS $(10 \mathrm{mM})$ & $7 \times 10^{-3}$ & 0.55 & 32 \\
\hline Porous Gold & LAC-hPG & PBS (10 mM) & $6 \times 10^{-3}$ & 0.6 & 33 \\
\hline GA/[Lac/PEI/Lac/CNT] & $\left.\mathrm{GA} /[\mathrm{GOx} / \mathrm{PEI}]_{2} / \mathrm{CNT}\right]$ & PBS (40 mM) & $35 \times 10^{-3}$ & 0.6 & 34 \\
\hline 3D Pt/MWCNTs & 3D Pt/MWCNTs & PBS (0.1 M) & $260 \times 10^{-3}$ & 1 & 35 \\
\hline TPA/HRP/GOx)]/PEI/CNT & TPA/HRP/GOx)]/PEI/CNT & $\operatorname{PBS}(0.2 \mathrm{M})$ & 2 & 0.8 & 36 \\
\hline 2D-GP & 2D-GP & PBS & $4 \times 10^{-3}$ & 0.66 & 37 \\
\hline Metallic cotton fibers & Metallic cotton fibers & PBS $(0.3 \mathrm{M})$ & 3.5 & - & 38 \\
\hline $\mathrm{CDH} / \mathrm{BOx}$ & $\mathrm{CDH} / \mathrm{BOx}$ & Saliva & $2.1 \times 10^{-3}$ & 0.63 & 39 \\
\hline $\mathrm{CDH} / \mathrm{BOx}$ & $\mathrm{CDH} / \mathrm{BOx}$ & Tears & $3.5 \times 10^{-3}$ & 0.57 & 39 \\
\hline \multirow{2}{*}{ GA } & \multirow{2}{*}{$\mathrm{Sm}_{2} \mathrm{O}_{3} / \mathrm{GA}$} & Saliva & $1.55 \times 10^{-3}$ & 0.6 & \multirow{2}{*}{ This work } \\
\hline & & PBS (3 m M) & $3.2 \times 10^{-3}$ & 0.3 & \\
\hline
\end{tabular}




\section{REFERENCES}

1. Guo, H.-L.; Wang, X.-F.; Qian, Q.-Y.; Wang, F.-B.; Xia, X.-H., A Green Approach to the Synthesis of Graphene Nanosheets. ACS Nano 2009, 3 (9), 2653-2659.

2. Bakandritsos, A.; Pykal, M.; Błoński, P.; Jakubec, P.; Chronopoulos, D. D.; Poláková, K.; Georgakilas, V.; Čépe, K.; Tomanec, O.; Ranc, V.; Bourlinos, A. B.; Zbořil, R.; Otyepka, M., Cyanographene and Graphene Acid: Emerging Derivatives Enabling High-Yield and Selective Functionalization of Graphene. ACS Nano 2017, 11 (3), 2982-2991.

3. Yamada, T.; Okigawa, Y.; Hasegawa, M.; Watanabe, K.; Taniguchi, T., Relationship Between Mobility and Strain in CVD graphene on h-BN. AIP Advances 2020, 10 (8), 085309.

4. $\quad$ Ferrari, A. C.; Basko, D. M., Raman Spectroscopy as a Versatile Tool for Studying the Properties of Graphene. Nature Nanotechnology 2013, 8 (4), 235-246.

5. Tan, Z.; Miao, G.; Liu, C.; Luo, H.; Bao, L.; Kong, L.; Sun, Y., Catalytic Conversion of Glucose Into Alkanediols over Nickel-Based Catalysts: A Mechanism Study. RSC Advances 2016, 6 (67), 62747-62753.

6. Brennan, L.; Corless, M.; Hewage, C.; Malthouse, J. P. G.; McClenaghan, N. H.; Flatt, P. R.; Newsholme, P., 13C NMR Analysis Reveals a Link Between L-Glutamine Metabolism, D-glucose Metabolism and Y-Glutamyl Cycle Activity in a Clonal Pancreatic Beta-Cell Line. Diabetologia 2003, 46 (11), 1512-1521.

7. Moreno, K. X.; Harrison, C. E.; Merritt, M. E.; Kovacs, Z.; Malloy, C. R.; Sherry, A. D., Hyperpolarized $\delta$-[113C]gluconolactone as a Probe of the Pentose Phosphate Pathway. NMR in Biomedicine 2017, 30 (6), e3713.

8. Narain, R.; Jhurry, D., Synthesis and Characterization of Novel Polymers Derived from Gluconolactone. Polymer International 2002, 51 (1), 85-91.

9. Zhu, H.; Li, L.; Zhou, W.; Shao, Z.; Chen, X., Advances in Nonenzymatic Glucose Sensors Based on Metal oxides. Journal of Materials Chemistry B 2016, 4 (46), 7333-7349.

10. Hwang, D.-W.; Lee, S.; Seo, M.; Chung, T. D., Recent Advances in Electrochemical Nonenzymatic Glucose Sensors - A review. Analytica Chimica Acta 2018, 1033, 1-34.

11. Vassilyev, Y. B.; Khazova, O. A.; Nikolaeva, N. N., Kinetics and Mechanism of Glucose Electrooxidation on Different Electrode-Catalysts: Part I. Adsorption and Oxidation on Platinum. Journal of Electroanalytical Chemistry and Interfacial Electrochemistry 1985, 196 (1), 105-125.

12. Lin, Y.; Hu, L.; Yin, L.; Guo, L., Electrochemical Glucose Biosensor with Improved Performance Based on the Use of Gucose Oxidase and Prussian Blue Incorporated Into a Thin Film of Self-polymerized Dopamine. Sens. Actuators B Chem. 2015, 210, 513-518.

13. Kong, F.-Y.; Gu, S.-X.; Li, W.-W.; Chen, T.-T.; Xu, Q.; Wang, W., A Paper Disk Equipped With Graphene/polyaniline/Au Nanoparticles/Glucose Oxidase Biocomposite Modified Screen-Printed Electrode: Toward Whole Blood Glucose Determination. Biosens. Bioelectron 2014, 56, 77-82.

14. Esmaeili, C.; Abdi, M. M.; Mathew, A. P.; Jonoobi, M.; Oksman, K.; Rezayi, M., Synergy Effect of Nanocrystalline Cellulose for the Biosensing Detection of Glucose. J. Sens. 2015, 15 (10), 24681-24697.

15. Tao, J.-Z.; Xu, G.-R.; Hao, H.-L.; Yang, F.-X.; Ahn, K.-S.; Lee, W.-Y., Poly (m-phenylenediamine)-Prussian Blue Hybrid Film Formed By One-step Electrochemical Deposition for Glucose Biosensor. Journal of Electroanalytical Chemistry 2013, 689, 96-102.

16. Sekar, N. C.; Shaegh, S. A. M.; Ng, S. H.; Ge, L.; Tan, S. N., A Paper-based Amperometric Glucose Biosensor Developed with Prussian Blue-Modified Screen-Printed Electrodes. Sens. Actuators B Chem. 2014, 204, 414-420.

17. Shen, X.; Xia, X.; Du, Y.; Ye, W.; Wang, C., Amperometric Glucose Biosensor Based on AuPd Modified Reduced Graphene Oxide/polyimide Film With Glucose Oxidase. J. Electrochem. Soc. 2017, 164 (6), B285.

18. Bäcker, M.; Rakowski, D.; Poghossian, A.; Biselli, M.; Wagner, P.; Schöning, M. J., Chip-based Amperometric Enzyme Sensor System for Monitoring of Bioprocesses by Flow-injection Analysis. J. Biotechnol. 2013, 163 (4), 371-376.

19. Wei, A.; Sun, X. W.; Wang, J.; Lei, Y.; Cai, X.; Li, C. M.; Dong, Z.; Huang, W., Enzymatic Glucose Biosensor Based on ZnO Nanorod Array Grown by Hydrothermal Decomposition. Appl. Phys. Lett 2006, 89 (12), 123902.

20. Hwa, K.-Y.; Subramani, B., Synthesis of Zinc Oxide Nanoparticles on Graphene-Carbon Nanotube Hybrid for Glucose Biosensor Applications. Biosens. Bioelectron 2014, 62, 127-133.

21. Marie, M.; Mandal, S.; Manasreh, O., An Electrochemical Glucose Sensor Based on Zinc Oxide Nanorods. Sensors 2015, 15 (8), 18714-18723.

22. Aini, B. N.; Siddiquee, S.; Ampon, K.; Rodrigues, K. F.; Suryani, S., Development of Glucose Biosensor Based on ZnO Nanoparticles Film and Glucose Oxidase-immobilized Eggshell Membrane. Sensing and Bio-Sensing Research 2015, 4, 46-56. 
23. Cui, H.-F.; Ye, J.-S.; Zhang, W.-D.; Li, C.-M.; Luong, J. H. T.; Sheu, F.-S., Selective and Sensitive Electrochemical Detection of Glucose in Neutral Solution Using Platinum-Lead Alloy Nanoparticle/carbon Nanotube Nanocomposites. Anal. Chim. Acta 2007, 594 (2), 175-183.

24. Kang, X.; Mai, Z.; Zou, X.; Cai, P.; Mo, J., A sensitive Nonenzymatic Glucose Sensor in Alkaline Media With a copper Nanocluster/multiwall Carbon Nanotube-Modified Glassy Carbon Electrode. Anal. Biochem 2007, 363 (1), 143-150.

25. Zhou, C.; Xu, L.; Song, J.; Xing, R.; Xu, S.; Liu, D.; Song, H., Ultrasensitive Nonenzymatic Glucose Sensor Based on Three-dimensional Network of ZnO-CuO Hierarchical Nanocomposites by Electrospinning. Sci. Rep 2014, $4,7382$.

26. Zhang, X.; Zhang, Z.; Liao, Q.; Liu, S.; Kang, Z.; Zhang, Y., Nonenzymatic Glucose Sensor Based on In Situ Reduction of Ni/NiO-graphene Nanocomposite. Sens 2016, 16 (11), 1791.

27. Chung, R.-J.; Wang, A.-N.; Liao, Q.-L.; Chuang, K.-Y., Nonenzymatic Glucose Sensor Composed of CarbonCoated Nano-zinc Oxide. J. Nanomater. 2017, 7 (2), 36.

28. Bag, S.; Baksi, A.; Nandam, S. H.; Wang, D.; Ye, X.; Ghosh, J.; Pradeep, T.; Hahn, H., Nonenzymatic Glucose Sensing Using Ni60Nb40 Nanoglass. ACS nano 2020, 14 (5), 5543-5552.

29. Chang, Q.; Zhang, P.; Mostaghimi, A. H. B.; Zhao, X.; Denny, S. R.; Lee, J. H.; Gao, H.; Zhang, Y.; Xin, H. L.; Siahrostami, S.; Chen, J. G.; Chen, Z., Promoting $\mathrm{H}_{2} \mathrm{O}_{2}$ Production via 2-electron Oxygen Reduction by Coordinating Partially Oxidized Pd with Defect Carbon. Nature Communications 2020, 11 (1), 2178.

30. Yuan, Y.; Wang, J.; Adimi, S.; Shen, H.; Thomas, T.; Ma, R.; Attfield, J. P.; Yang, M., Zirconium Nitride Catalysts Surpass Platinum for Oxygen Reduction. Nature Materials 2020, 19 (3), 282-286.

31. Ohayon, D.; Nikiforidis, G.; Savva, A.; Giugni, A.; Wustoni, S.; Palanisamy, T.; Chen, X.; Maria, I. P.; Di Fabrizio, E.; Costa, P. M., Biofuel Powered Glucose Detection in Bodily Fluids With an n-type Conjugated Polymer. Nature materials 2020, 19 (4), 456-463.

32. Pinyou, P.; Conzuelo, F.; Sliozberg, K.; Vivekananthan, J.; Contin, A.; Pöller, S.; Plumeré, N.; Schuhmann, W., Coupling of An Enzymatic Biofuel cell to An Electrochemical cell for Self-Powered Glucose Sensing With Optical Readout. Bioelectrochemistry 2015, 106, 22-27.

33. du Toit, H.; Di Lorenzo, M., Glucose Oxidase Directly Immobilized onto Highly Porous Gold Electrodes for Sensing and Fuel Cell applications. Electrochimica Acta 2014, 138, 86-92.

34. Christwardana, M.; Kim, K. J.; Kwon, Y., Fabrication of Mediatorless/Membraneless Glucose/Oxygen Based Biofuel Cell using Biocatalysts Including Glucose Oxidase and Laccase Enzymes. Scientific Reports 2016, 6 (1), 30128.

35. Zhao, Y.; Fan, L.; Gao, D.; Ren, J.; Hong, B., High-Power Nonenzymatic Glucose Biofuel Cells Based on Three-Dimensional Platinum Nanoclusters Immobilized on Multiwalled Carbon Nanotubes. Electrochimica Acta 2014, 145, 159-169.

36. Chung, Y.; Tannia, D. C.; Kwon, Y., Glucose Biofuel Cells Using Bi-enzyme Catalysts Including Glucose Oxidase, Horseradish Peroxidase and Terephthalaldehyde Crosslinker. Chemical Engineering Journal 2018, 334, 1085-1092.

37. Shen, F.; Pankratov, D.; Halder, A.; Xiao, X.; Toscano, M. D.; Zhang, J.; Ulstrup, J.; Gorton, L.; Chi, Q., Two-dimensional Graphene Paper Supported Flexible Enzymatic Fuel Cells. Nanoscale Advances 2019, 1 (7), $2562-$ 2570.

38. Kwon, C. H.; Ko, Y.; Shin, D.; Kwon, M.; Park, J.; Bae, W. K.; Lee, S. W.; Cho, J., High-power Hybrid Biofuel Cells using Layer-by-layer Assembled Glucose Oxidase-Coated Metallic Cotton Fibers. Nature Communications 2018, 9 (1), 4479.

39. Falk, M.; Blum, Z.; Shleev, S., Direct Electron Transfer Based Enzymatic Fuel Cells. Electrochimica Acta 2012, 82, 191-202. 